\title{
Chapter 6 \\ The Role of Immunity and Inflammation in IPF Pathogenesis
}

\author{
Marcus W. Butler and Michael P. Keane
}

There has been a revolution in the prevailing concensus regarding the pathogenesis of IPF over the course of the past couple of decades, with a retreat from paradigms solely based on IPF as an immune-mediated disorder involving chronic inflammation of the lower airways which progresses to fibrosis, towards a view of IPF as a disease of abnormal pulmonary fibroproliferation/disorganised matrix deposition in the face of repetitive injury to an ageing alveolar epithelium that is genetically predisposed to UIP formation [1-4] (Fig. 6.1). The historical term "cryptogenic fibrosing alveolitis" used interchangeably with IPF encapsulates the thinking decades ago when much of the available evidence pointed to a likely dominant role for chronic alveolar epithelial inflammation progressing to injury and dysregulated repair resulting in fibrosis, not least of all because alveolar inflammation appeared to precede fibrotic lesion development [5]. Initial enthusiasm for a chronic inflammatory basis for IPF also stemmed from observations of an excess of neutrophils within alveolar walls and the alveolar epithelial surfaces in IPF [6]. In addition, immune complexes of mainly IgG were found in the epithelial lining fluid of IPF individuals [7]. In an older study, alveolar inflammation was found to occur in approximately half of clinically unaffected family members who are at risk of inheriting autosomal dominant idiopathic pulmonary fibrosis, termed familial interstitial pneumonia (FIP) [8]; however a more recent larger study (FIP defined as at least two family members with IIP including IPF in at least one affected individual per family) failed to replicate this finding, with no difference seen in inflammatory cell proportions in BAL fluid among at-risk (asymptomatic first-degree relatives of FIP patients) and healthy control subjects [9]. Part of the shift away from the notion of chronic inflammation as a basis for IPF came with the tighter concensus surrounding the pathologic classification of the disease two decades ago, which up to then had included

M. W. Butler · M. P. Keane ( $ه)$

Department of Medicine, University College Dublin and St. Vincent's University Hospital,

Dublin, Dublin, Ireland

e-mail: michael.P.keane@udc.ie 


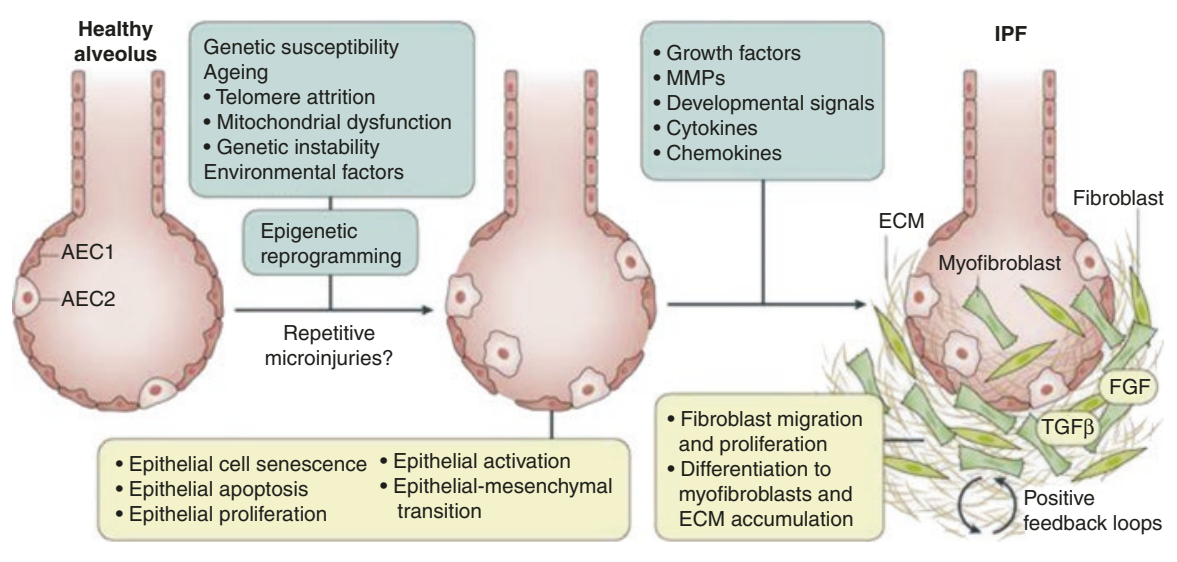

Nature Reviews I Disease Primers

Fig. 6.1 A proposed pathogenetic model of idiopathic pulmonary fibrosis. (From Ref. [4])

what are now widely accepted as being separate forms of idiopathic interstitial pneumonia such as non-specific interstitial pneumonia and acute interstitial pneumonia, for which anti-inflammatory treatments may show more benefit [10-12]. A sentinel event in shaping the current prevailing view that immunomodulatory therapies are to be avoided in IPF came with the discovery in the PANTHER study that a then standard-of-care though unproven therapy for IPF, the combination of oral corticosteroid, azathioprine and $\mathrm{N}$-acetylcysteine was not only inefficacious in IPF but led to higher mortality and hospitalisation within a mean of only 32 weeks of treatment versus placebo [13]. The dawn of a new era of therapeutic options for what was until then an untreatable disease arrived on May 18, 2014, with the simultaneous publication of phase III studies of two very different disease modification compounds, pirfenidone and nintedanib, which both share antifibrotic properties and have highly pleiotropic mechanisms of action, suggestive of a need in IPF to address multiple redundant wound-healing pathways in order to control what is a complex polygenic disorder $[14,15]$. Nearly all of the compounds currently in development for the treatment of IPF involve mechanisms relating to lung tissue repair, regeneration, inhibition of epithelial cell apoptosis and inhibition of collagen deposition, with little interest in an anti-inflammatory/immunosuppressing approach [2], given the unequivocal failures of such approaches in the past [13, 16]. Within these few years, long-held theories of IPF pathogenesis had been overturned.

The delight that universally accompanied the long-awaited emergence of IPF medications with some disease-modifying effects needs to be tempered against the ongoing unmet needs of these patients, who are far from cured by current antifibrotic strategies. Somewhat at odds with a more dismissive view of an immunologic and inflammatory role in IPF pathogenesis are a wealth of data that provides the smoking gun to an immunobiological role in either the initiation or progression of IPF, which remains incompletely understood and, arguably therefore, unsuccessfully addressed in treatment approaches. Such a role may be more important for 
subtypes of IPF that await elucidation, though it is also plausible that the association of immunologic abnormalities with IPF are a process that is downstream from fibrosis-driven biology $[2,17]$. Strongly pointing towards a chronic immune process in IPF are the replicated observations in IPF lung tissue of lymphoid aggregates, suggestive of lymphoid neogenesis [17-20]. These are found in close proximity to fibroblastic foci and are composed of mainly activated $\mathrm{CD}^{+} \mathrm{T}$ lymphocytes and mature dendritic cells, with a subset of activated CD20 $0^{+}$cells, with some evidence also pointing to chemokine receptor (CCR)6 expression in these infiltrates, as found on memory T cells, Th-17 cells, B cells and dendritic cells [18, 20] (Fig. 6.2). These aggregates were seen in increasing numbers in IPF explants versus less advanced IPF lung surgical biopsy specimens, suggestive of a sustained role for such lymphoid tissue in progressive IPF [19]. The picture is confused however by the observation that these tertiary lymphoid structures (TLS) contain non-proliferating and non-apoptotic mature $\mathrm{CD}^{4} 5 \mathrm{RO}^{+} \mathrm{T}$ and $\mathrm{B}$ cells $[18,19]$, which has led to a hypothesis of these cells homing to the lung from the systemic circulation, although data is lacking to support such an origin [19].

Another difficulty in dismissing an important role for the immune system in IPF lies in the repeated observation of areas of histopathologic UIP and non-specific interstitial pneumonia (NSIP) in the same patient when biopsies are obtained from
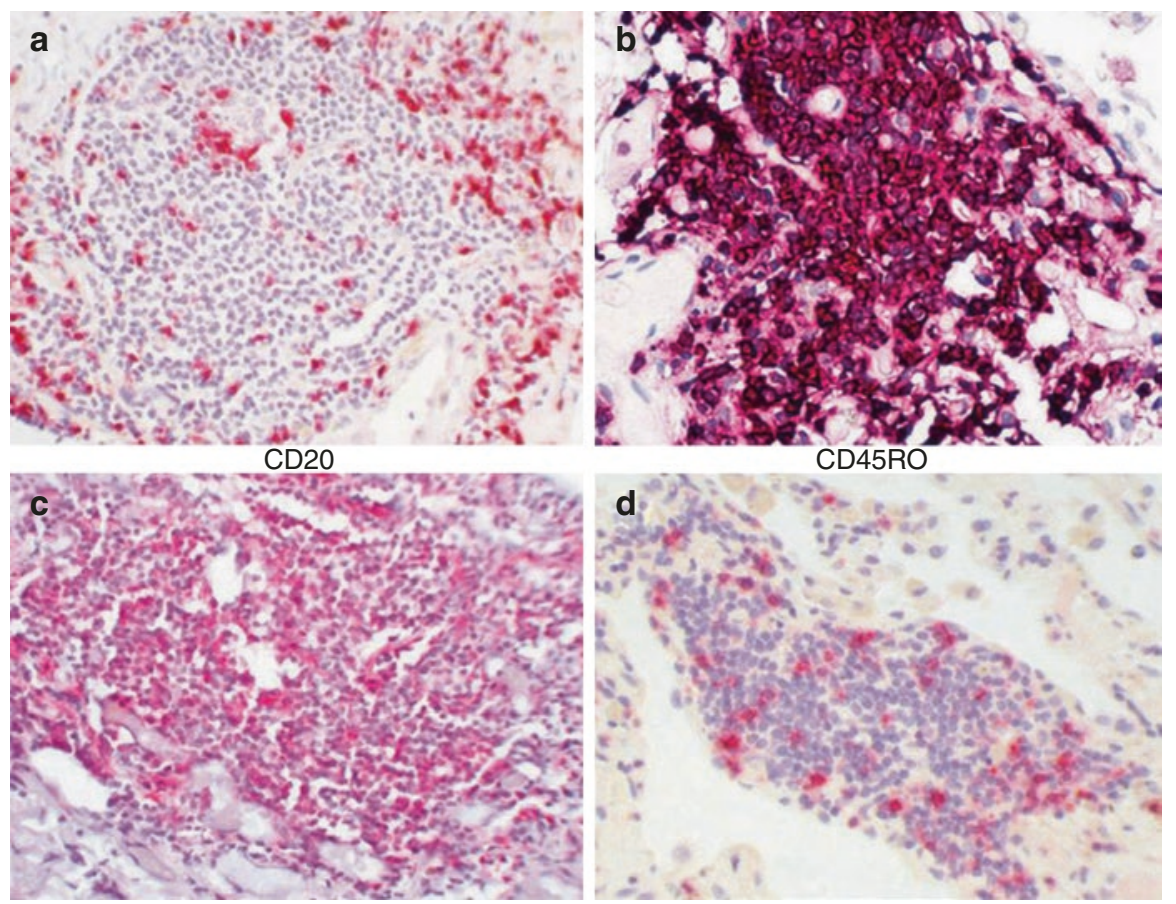

Fig. 6.2 Idiopathic pulmonary fibrosis inflammatory infiltrates. All photomicrographs show the tissue stained with Fast Red and haematoxylin counterstain. $(\mathbf{a}-\mathbf{f})$ The photos have a magnification of $\times 200$. ( $\mathbf{g}, \mathbf{h})$ The photos have a magnification of $\times 400$. (From Ref. [20]) 


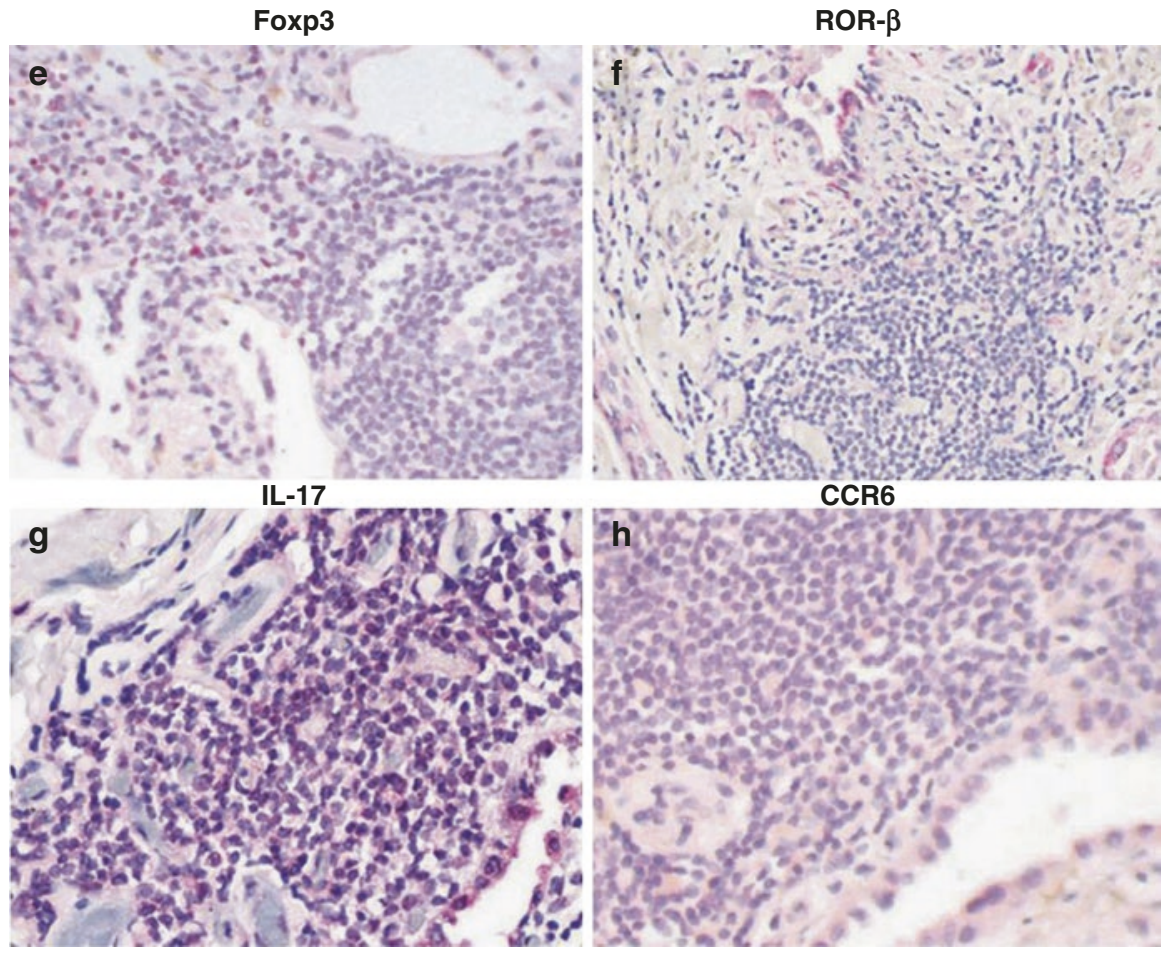

Fig. 6.2 (continued)

different lobar locations, a phenomenon thought to occur in $13-26 \%$ of cases [21, 22]. NSIP can have varying degrees of alveolar wall inflammation by predominantly lymphocytes and plasma cells in addition to fibrosis and has a better prognosis than UIP, but individuals with discordant UIP and NSIP on their multiple biopsies have a poor prognosis similar to those with concordant UIP on multiple biopsies $[21,22]$. In support of an endotypic difference among the two diseases, NSIP fibroblasts appear to behave more like normal fibroblasts than is seen in IPF fibroblasts, where the latter exhibit greater contractility and secrete greater amounts of fibronectin and TGF- $\beta 1$ [23]. There is a great need to further improve our understanding of the potential for an evolution of NSIP into fibrotic NSIP and later into UIP, as immunomodulatory therapy for NSIP, a putative early treatment strategy for IPF, demonstrates some efficacy versus being ineffective in UIP [24]. Some have suggested that a greater understanding of rheumatoid arthritis-associated interstitial lung disease, where the undoubtedly inflammatory disease of rheumatoid arthritis can result in either an NSIP or UIP pattern, offers a good model for gaining further insight into the pathogenesis of both of these related interstitial pneumonias [25]. Lending support of such a model, a recent study that established and validated a role for a biomarker index of three plasma molecules, MMP-7, surfactant protein D and osteopontin in discriminating IPF from alternative interstitial lung diseases (adjusted 
area under the curve of 0.766, excluding RA-ILD), could not distinguish IPF from RA-ILD [26]. Of interest in such an IPF model is the shared risk factor of chronic tobacco smoke exposure in both idiopathic and RA-associated UIP. In recent times, the contributory role of immune mediators and inflammatory cells have once again gained more acceptance in schemata of IPF pathogenesis, though far more questions than answers are found [27]. The remainder of this chapter will discuss the evidence that implicates a variety of inflammatory and immunologic processes in contributing to the pathogenesis of IPF.

\section{Innate Immunity and Altered Host Defence Mechanisms}

In IPF, a repetitive cycle of local micro-injury to ageing alveolar epithelium by various factors and processes including cigarette smoke, environmental exposures, microbial colonisation/infection, microaspiration, endoplasmic reticulum stress and oxidative stress is believed to underpin the development of disease, with resultant aberrant wound healing [1]. A prototypic example of how such a diverse array of stressors can mediate tissue injury via innate immune mechanisms is the Tolllike receptor family of pattern-recognition receptors that recognise pathogen-associated molecular patterns (PAMPs) from microbes or danger-associated molecular patterns (DAMPs) from damaged tissues (Fig. 6.3) [28]. In the case of IPF, a frontline cell in this process is the type II alveolar epithelial (AEC2) cell, a pulmonary form of stem cell capable of long-term self-renewal, and in IPF, the majority of such cells exhibit evidence of apoptosis [29, 30]. In healthy innate immune systems, these AEC2 cells are recognised and phagocytosed in a non-inflammatory process known as efferocytosis [31]. Critical to the regulation of lung-injury response is the interaction of the evolutionarily conserved danger recognition receptor termed Toll-like receptor (TLR) 4 with the DAMP known as hyaluronan, a glycosaminoglycan that maintains structural integrity of the lung extracellular matrix but which is elevated in BAL fluid in IPF patients where it correlates with disease severity $[32,33]$. A widely used model of experimental IPF is the use of the cancer chemotherapy agent bleomycin, instilled into mice to bring about oxidative DNA damage, cell death of alveolar macrophages and airway epithelial cells with ensuing fibrosis. In a bleomycin-induced lung fibrosis model where organoids were created from highly purified AEC2 cells, the hyaluronan-TLR4 axis was shown to play a key role in lung stem cell renewal, and perturbation of this axis by deletion of the hyaluronan synthase 2 (HAS2) enzyme led to worsened fibrosis. The same authors also demonstrated that AEC2 cells from IPF patients studied in organoid cultures had reduced HAS2 and hyaluronan expression and reduced renewal capacity (See Fig. 6.4) [33, 34].

A familial form of IPF has been linked to damaged AEC2 cells associated with a mutation in the surfactant protein $\mathrm{C}$ gene [35]. Ineffective repair of damaged alveolar epithelium leading to pulmonary fibrosis is supported by the observations made in a transgenic mouse model expressing human diphtheria toxin receptor on AEC2 


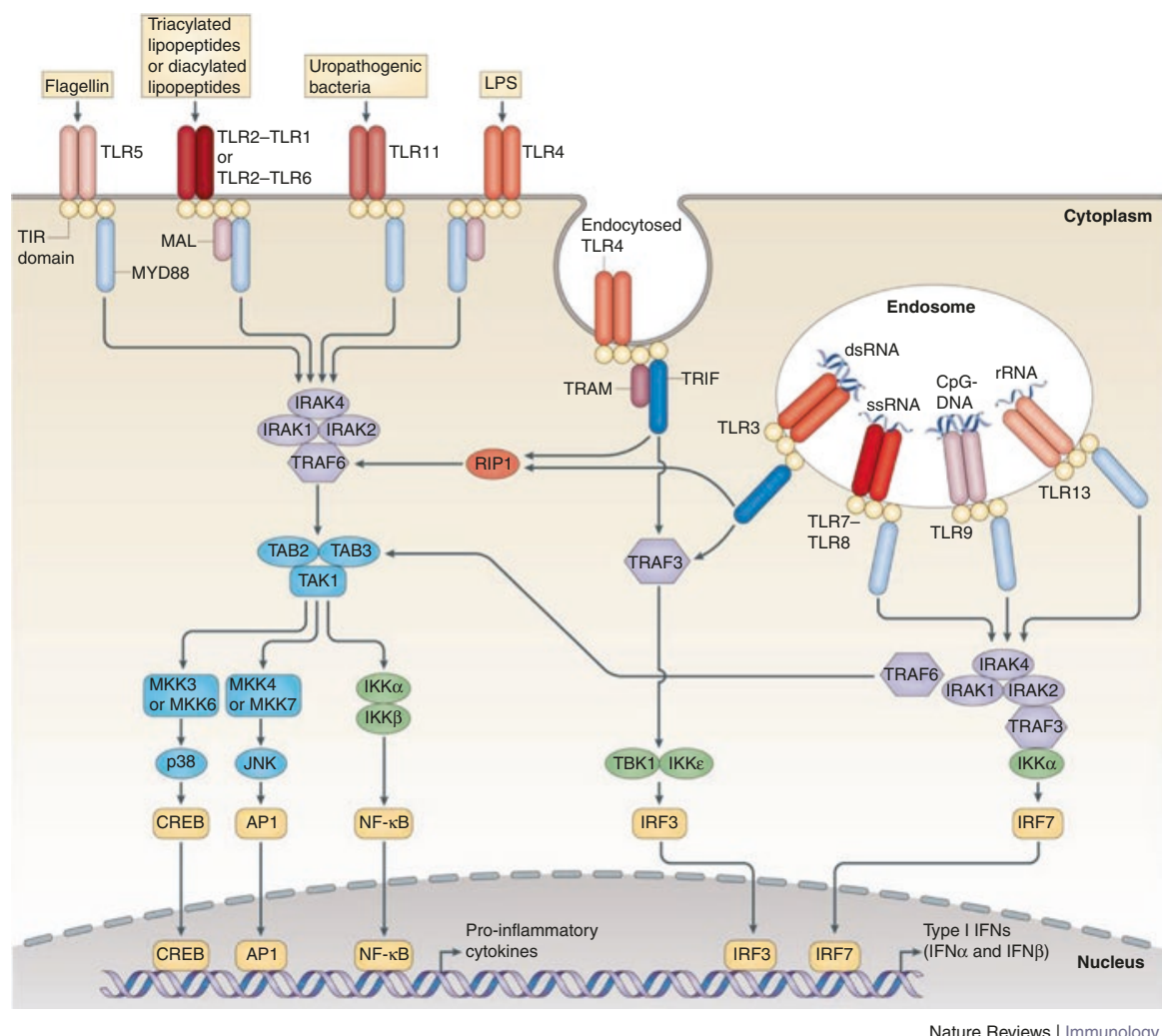

Fig. 6.3 A detailed knowledge of how mammalian Toll-like receptors (TLRs) signal has developed over the past 15 years. TLR5, TLR11, TLR4, and the heterodimers of TLR2-TLR1 or TLR2TLR6 bind to their respective ligands at the cell surface, whereas TLR3, TLR7-TLR8, TLR 9 and TLR 13 localise to the endosomes, where they sense microbial and host-derived nucleic acids. TLR4 localises at both the plasma membrane and the endosomes. TLR signalling is initiated by ligand-induced dimerisation of receptors. Following this, the Toll-IL-1-resistance (TIR) domains of TLRs engage TIR domain-containing adaptor proteins (either myeloid differentiation primaryresponse protein 88 (MYD88) and MYD88-adaptor-like protein (MAL) or TIR domain-containing adaptor protein inducing IFN $\beta$ (TRIF) and TRIF-related adaptor molecule (TRAM)). TLR4 moves from the plasma membrane to the endosomes in order to switch signalling from MYD88 to TRIF. Engagement of the signalling adaptor molecules stimulates downstream signalling pathways that involve interactions between IL-1R-associated kinases (IRAKs) and the adaptor molecules TNF receptor-associated factors (TRAFs), and that lead to the activation of the mitogen-activated protein kinases (MAPKs) JUN N-terminal kinase (JNK) and p38, and to the activation of transcription factors. Two important families of transcription factors that are activated downstream of TLR signalling are nuclear factor- $\mathrm{KB}(\mathrm{NF}-\mathrm{KB})$ and the interferon-regulatory factors (IRFs), but other transcription factors, such as cyclic AMP-responsive element-binding protein (CREB) and activator protein 1 (AP1), are also important. A major consequence of TLR signalling is the induction of pro-inflammatory cytokines, and in the case of the endosomal TLRs, the induction of type I interferon (IFN). dsRNA double-stranded RNA, IKK inhibitor of NF-kB kinase, LPS lipopolysaccharide, MKK MAP kinase kinase, RIP1 receptor-interacting protein 1, rRNA ribosomal RNA, ssRNA single-stranded RNA, TAB TAK1-binding protein, TAK TGF $\beta$-activated kinase, TBK1 TANK-binding kinase 1. (From Ref. [28]) 


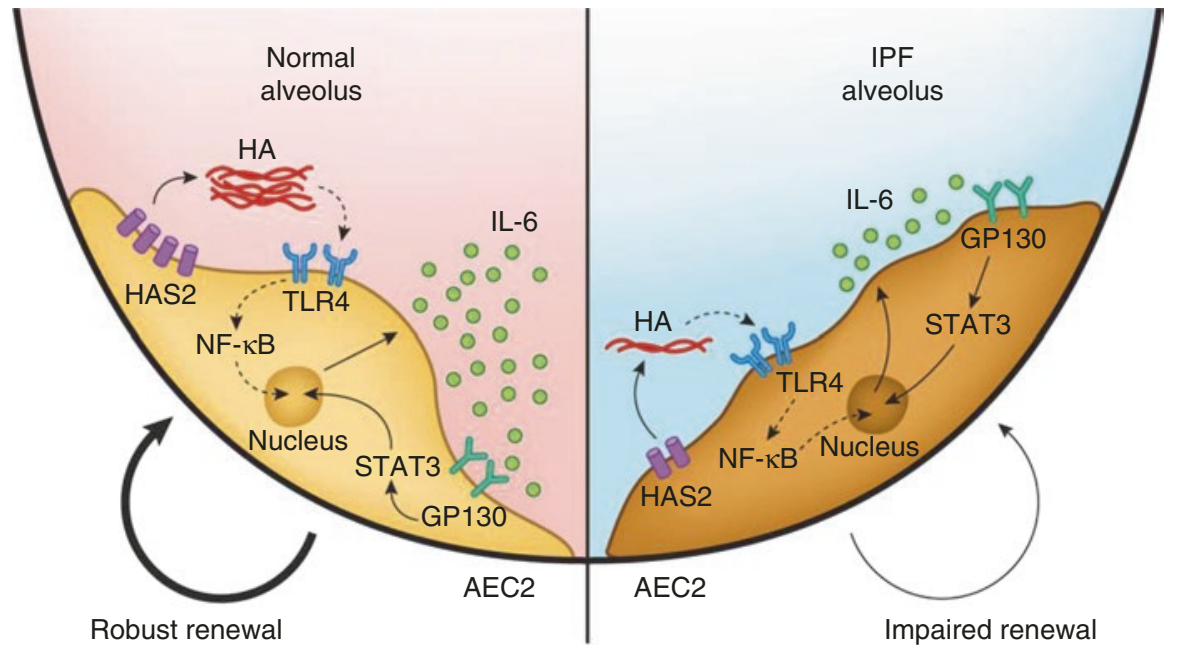

Fig. 6.4 In healthy AEC2 cells, regenerative capacity is maintained by hyaluronan synthase 2 (HAS2)-mediated production of HA, which interacts with Toll-like receptor 4 (TLR4). This in turn results in the expression of IL-6 (either indirectly or directly). In IPF-derived AEC2 cells, HAS2 expression is reduced, which causes decreased regenerative and impaired response to injury.

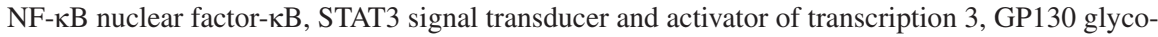
protein 130, AEC2 type 2 alveolar epithelial cell. (From Ref. [33])

cells, where administration of diphtheria toxin to these animals resulted in AEC2 cell injury and pulmonary fibrosis [36]. Among the more developed compounds currently being evaluated as investigational new drugs for IPF is a small molecule BMS-986020 antagonising a lysophosphatidic acid receptor (LPA1) in an effort to inhibit the airway epithelial cell apoptosis observed in IPF, among its many other mechanisms of action (Phase II Trial number: NCT01766817) [2, 37].

Based on the fact that gut commensal bacteria are known to influence stem cell renewal in intestinal epithelium through TLR4 interactions with microbiome components, it is plausible that the lung microbiome could influence alveolar epithelial homeostasis that is perturbed in IPF [33]. MUC5B is a gel-forming mucin that constitutes a major component of airway mucus, and along with MUC1 is the most highly expressed mucin gene in distal human airways [38]. It normally plays a key role in innate defence of airway epithelial mucosa but is overexpressed in IPF lungs [39]. A large-scale genome-wide association study [40] of idiopathic interstitial pneumonia (IIP) cases (mostly IPF) versus controls revealed common genetic variations associated with risk for IIP, including a T/G SNP in the MUC5B promoter (rs35705950), a region which has been identified previously as a risk locus for IIP [39]. A meta-analysis has since shown that the MUC5B rs35705950 polymorphism confers susceptibility to IPF in those of European or Asian genetic ancestry, and the same SNP is associated with progression of subclinical interstitial lung abnormalities on serial CT scans, though conversely also associated with improved survival in IPF [41-43]. A recent systems biology study incorporating a novel modified aptamer 
technology to study proteomic differences among blood of 60 IPF subjects and 21 normal subjects pointed to a host defence defect in IPF versus normals, with greatest enrichment, among all downregulated proteins, for those governing host defence, potentially indicative of attempts in IPF to restrict airway epithelial damage and initiate reparative processes [44] (Fig. 6.5). In addition to the MUC5B SNP, other polymorphisms in genes related to epithelial integrity and host defence have been

\section{a}

\begin{tabular}{|c|c|c|c|c|c|c|c|}
\hline Category Term & Count & $\%$ & Fold enrichment & Bonferroni & $\mathrm{BH}$ & FDR & Kappa \\
\hline GO BP GO:0006952 defense response & 25 & 22 & 4.87 & $2.25 \mathrm{E}-07$ & $2.25 \mathrm{E}-07$ & $2.56 \mathrm{E}-07$ & 1.00 \\
\hline GO BP GO:0006916 anti-apoptosis & 14 & 12 & 8.14 & 2.14E-05 & 1.07E-05 & $2.43 \mathrm{E}-05$ & \\
\hline GO BP GO:0006955 immune response & 23 & 20 & 3.99 & 5.93E-05 & $1.98 \mathrm{E}-05$ & $6.74 \mathrm{E}-05$ & 0.47 \\
\hline GO MF GO:0005125 cytokine activity & 13 & 11 & 8.09 & $1.76 \mathrm{E}-05$ & $1.76 \mathrm{E}-05$ & $8.02 \mathrm{E}-05$ & \\
\hline GO BP GO:0009611 response to wounding & 20 & 17 & 4.52 & $9.25 \mathrm{E}-05$ & $2.31 \mathrm{E}-05$ & $1.05 \mathrm{E}-04$ & 0.59 \\
\hline GO BP GO:0032101 regulation of response to external stimulus & 12 & 10 & 9.04 & 1.15E-04 & $2.30 \mathrm{E}-05$ & $1.31 \mathrm{E}-04$ & \\
\hline GO BP GO:0042127 regulation of cell proliferation & 24 & 21 & 3.65 & $1.36 \mathrm{E}-04$ & 2.27E-05 & $1.55 \mathrm{E}-04$ & \\
\hline GO BP GO:0042981 regulation of apoptosis & 24 & 21 & 3.57 & 2.01E-04 & $2.87 \mathrm{E}-05$ & $2.28 \mathrm{E}-04$ & \\
\hline GO BP GO:0043067 regulation of progeammed cell death & 24 & 21 & 3.54 & $2.40 \mathrm{E}-04$ & $3.00 \mathrm{E}-05$ & $2.72 \mathrm{E}-04$ & \\
\hline GO BP GO:0010941 regulation of cell death & 24 & 21 & 3.53 & $2.56 \mathrm{E}-04$ & $2.84 \mathrm{E}-05$ & $2.91 \mathrm{E}-04$ & \\
\hline
\end{tabular}

\section{b}
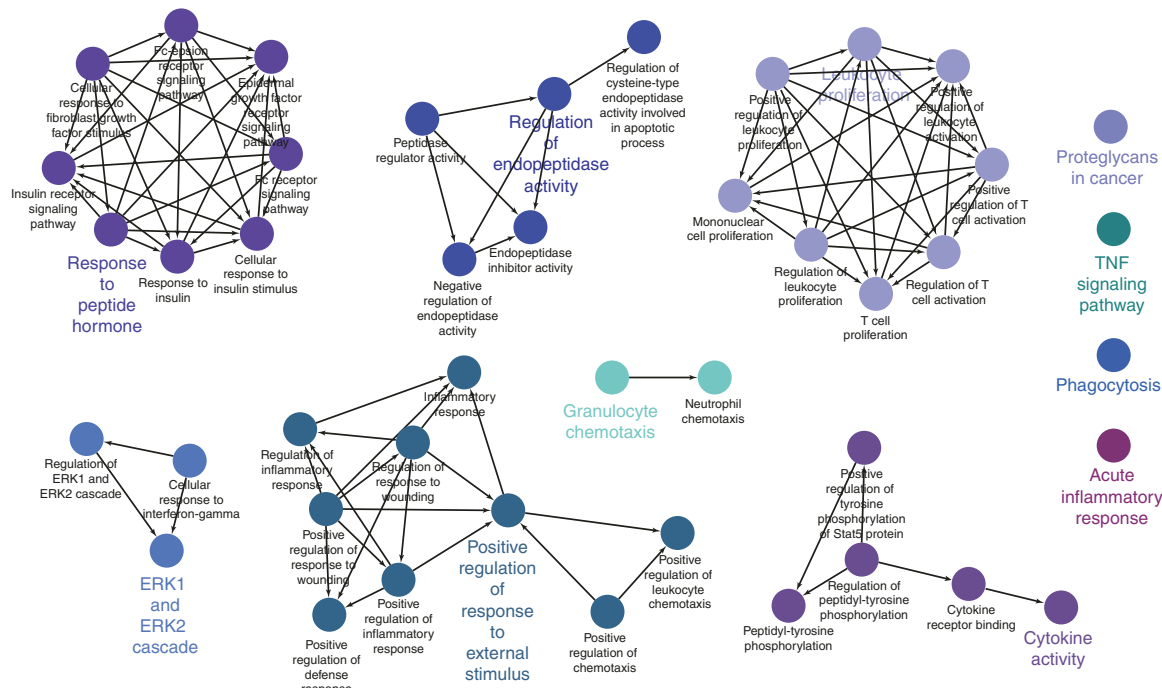

Fig. 6.5 Enrichment and network analysis of the downregulated IPF plasma proteome. (a) DAVID enrichment analysis was employed to select the most significantly enriched terms within the sample of downregulated proteins $(n=116)$. Bonferroni-corrected $P$ value, BH $P$ value and FDRs are reported. Kappa statistics reporting similarity to most significant term (low $>0.25$, moderate 0.25 0.5 , high $0.5-0.75$, very high $0.75-1$ ). (b) ClueGO visualisation and analysis of biological role (GO, Kegg pathways) was undertaken. GO terms are mapped in clusters by Kappa statistics. [Hexagon $=$ Kegg pathway, Ellipse $=$ Gene ontology term, arrow depicts direction of association $]$. The major overview term (smallest $P$ value within cluster) is depicted in colour. Node size depicts Bonferroni-corrected $P$ value $<0.0005$ for all terms reported. Further details can be found in online supplement. (From Ref. [44]) 
identified as predisposing to IPF, such as the TOLLIP rs5743890 polymorphism $[39,40,43,45]$. TOLLIP, a key modulator of innate immune responses, activates MYD88-dependent NF- $\mathrm{kB}$ to regulate TLR signalling and also antagonises TGF- $\beta$ signalling, in addition to roles in intracellular trafficking via SMAD7 and a role in governing antigen-specific proliferation of T cells and/or B cells [46-48]. TOLLIP is also one of many gene regions that exhibit differential hypomethylation of $\mathrm{CpG}$ islands in IPF lung tissues compared to control lungs assessed by $\mathrm{CpG}$ island microarray [49]. In a discovery genome-wide association study and subsequent independent replication case-control studies with over a thousand IPF patients and over 1200 control subjects, three TOLLIP SNPs were among a handful of SNPs that remained significantly associated with IPF susceptibility, including one SNP that was also associated with IPF mortality (rs5743890), with these polymorphisms regulating TOLLIP gene expression levels in IPF [45].

The links between Toll-like signalling and IPF pathogenesis have further grown in recent years with the observation that the functional TLR3 polymorphism rs3775291, which results in defective NF-kB and IRF3 activation, is associated with increased mortality risk and accelerated decline in FVC in patients with IPF [50]. The same authors examined human IPF fibroblasts that were wild-type, heterozygous or homozygous for the rs3775291 mutation in addition to utilising a murine bleomycin model of lung fibrosis that included TLR3 knockout (TLR3-/-) mice and demonstrated defective fibroproliferative responses and impaired interferon gamma responses in the fibroblasts with alleles for rs3775291 and worsened lung fibrosis and mortality in TLR3-/- mice [50].

Independent groups have shown associations among the lung microbiome and IPF [51-54]. Han and co-investigators had obtained BAL fluid from 55 subjects with moderately severe IPF in the prospectively recruited COMET-IPF study and, in a manner not pre-specified, carried out subsequent bacterial 16 ribosomal RNA pyrosequencing to characterise the microbiome, with IPF progression defined as a composite of deteriorating pulmonary function tests (relative decrease in FVC or DLCO of $\geq 10 \%$ or $\geq 15 \%$, respectively), death, acute exacerbation or lung transplantation. Using principal components analysis, they showed significant associations of IPF progression with increased relative abundance of a Streptococcus operational taxonomic unit (OTU) and a Staphylococcus OTU [51]. The same group more recently explored host immune responses in a given lung microbiome context using paired samples of peripheral blood mononuclear cell (PBMC) gene expression profiles and their BAL microbiome data, in addition to lung fibroblasts cultured from transbronchial biopsies, and found that immune response pathways including NOD-like receptor, TLR and RIG-like receptor signalling pathways were downregulated in association with worse progression-free survival (PFS). Their data showed that lung microbes with increased abundance and decreased community diversity were associated with decreased PBMC transcriptomic expression of immune pathways and shorter PFS. This study also provided data to support the idea that host-microbiome interactions might influence immune-mediated resident fibroblast responsiveness to TLR9 stimulation using CpG oligodeoxynucleotide [53]. 
Herpesviruses, a highly prevalent group of viruses, have frequently been found to be associated with the much rarer entity of IPF, suggesting a possible gene-environment interaction, with plausibility coming from the known life-long latency in the host that follows infection, potentially leading to a reactivation phenomenon in old age as a potential aetiologic trigger in susceptible individuals [55]. Among the evidence for this is the study from Kropski et al. that evaluated 75 asymptomatic at-risk first-degree relatives of FIP patients alongside 12 sporadic IPF patients and 27 healthy control subjects, which found a 14\% prevalence of early interstitial lung abnormalities on high-resolution chest CT scanning and over $35 \%$ with abnormalities such as peribronchiolar and interstitial fibrosis on transbronchial biopsies in the at-risk subjects. In this study, quantitative polymerase chain reaction was used on DNA isolated from cell-free BAL supernatant and demonstrated lowest quantities of herpesviruses in normals, intermediate quantities in the at-risk subjects and highest copies of herpesviruses per millilitre of BAL fluid in those with IPF, suggestive of ongoing viral replication in those with and at risk of a UIP lung disease and compatible with a greater burden of virus mediating a greater extent of airway epithelial cell injury. For at-risk subjects, a correlation was seen among endoplasmic reticulum (ER) stress markers and herpesvirus antigens using immunohistochemical analysis of transbronchial biopsies, consistent with a mechanism of virus-mediated epithelial cell injury [9]. None of these studies, though suggestive, can prove a causal link between microbes and IPF but could support the hypothesis that dysbiosis plays a role in IPF pathogenesis, if, for example, host defence proteins are being downregulated in a given microbiomic context.

\section{Chemotactic Cytokines}

Leukocyte infiltration is a universally recognised hallmark of inflammation. Once recruited to lung tissues, leukocytes can contribute to the pathogenesis of chronic inflammation and promote fibrogenesis via the elaboration of various cytokines. Maintenance of leukocyte recruitment during inflammation requires the cell surfaces to express adhesion molecules and the production of chemotactic molecules termed chemokines [56, 57]. Chemokines can be subdivided into four families$\mathrm{CXC}, \mathrm{CC}, \mathrm{C}$ and $\mathrm{CXXXC}$ - and these function as potent chemotactic factors for a variety of cell types including neutrophils, eosinophils, basophils, monocytes, mast cells, dendritic cells, NK cells and T and B lymphocytes (Table 6.1). The members of the four chemokine families exhibit approximately 20-40\% homology [58]. Chemokines are elaborated from an array of cells, including monocytes, neutrophils, alveolar macrophages, eosinophils, mast cells, T and B lymphocytes, NK cells, platelets and various structural cells, including keratinocytes, epithelial cells, mesangial cells, hepatocytes, fibroblasts, mesothelial cells, smooth muscle cells and endothelial cells. The ability of both immune and nonimmune cells to produce these chemokines supports the contention that such cytokines may play a pivotal role in orchestrating chronic inflammation [59]. 
Table 6.1 The four families of human chemokines: C, CC, CXC and CXXXC [57]

\begin{tabular}{|c|c|}
\hline Systemic name & Human ligand name \\
\hline \multicolumn{2}{|c|}{ The $\mathrm{C}$ chemokines } \\
\hline XCL1 & Lymphotactin \\
\hline XCL2 & SCM-1 $\beta$ \\
\hline \multicolumn{2}{|c|}{ The CC chemokines } \\
\hline CCL1 & I-309 \\
\hline CCL2 & Monocyte chemotactic protein-1 (MCP-1) \\
\hline CCL3 & Macrophage inflammatory protein-1 alpha (MIP-1 $\alpha)$ \\
\hline CCL4 & Macrophage inflammatory protein-1 beta (MIP-1 $\beta)$ \\
\hline CCL5 & Regulated on activation normal T-cell expressed and secreted (RANTES) \\
\hline CCL7 & Monocyte chemotactic protein-3 (MCP-3) \\
\hline CCL8 & Monocyte chemotactic protein-2 (MCP-2) \\
\hline CCL9 & 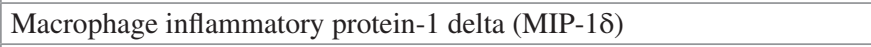 \\
\hline CCL11 & Eotaxin \\
\hline CCL13 & Monocyte chemotactic protein-4 (MCP-4) \\
\hline CCL14 & $\mathrm{HCC}-1$ \\
\hline CCL15 & HCC-2 \\
\hline CCL16 & HCC-4 \\
\hline CCL17 & Thymus and activation-regulated chemokine (TARC) \\
\hline CCL18 & DC-CK-1 \\
\hline CCL19 & Macrophage inflammatory protein-3 beta (MIP-3 $\beta$ ) \\
\hline CCL20 & Macrophage inflammatory protein-3 alpha (MIP-3 $\alpha$ ) \\
\hline CCL21 & 6Ckine \\
\hline CCL22 & MDC \\
\hline CCL23 & MPIF-1 \\
\hline CCL24 & MPIF-2 \\
\hline CCL25 & TECK \\
\hline CCL26 & Eotaxin-3 \\
\hline CCL27 & CTACK \\
\hline CCL28 & MEC \\
\hline \multicolumn{2}{|c|}{ The CXC chemokines } \\
\hline CXCL1 & Growth-related oncogene alpha (GRO- $\alpha)$ \\
\hline CXCL2 & Growth-related oncogene beta $(\mathrm{GRO}-\beta)$ \\
\hline CXCL3 & Growth-related oncogene gamma (GRO- $\gamma)$ \\
\hline CXCL4 & Platelet factor-4 (PF4) \\
\hline CXCL5 & Epithelial neutrophil-activating protein-78 (ENA-78) \\
\hline CXCL6 & Granulocyte chemotactic protein-2 (GCP-2) \\
\hline CXCL7 & Neutrophil-activating protein-2 (NAP-2) \\
\hline CXCL8 & Interleukin-8 (IL-8) \\
\hline CXCL9 & Monokine induced by interferon- $\gamma$ (MIG) \\
\hline CXCL10 & Interferon- $\gamma$-inducible protein (IP-10) \\
\hline CXCL11 & Interferon-inducible T-cell alpha chemoattractant (ITAC) \\
\hline
\end{tabular}


Table 6.1 (continued)

\begin{tabular}{l|l}
\hline Systemic name & Human ligand name \\
\hline CXCL12 & Stromal cell-derived factor-1 (SDF-1) \\
\hline CXCL13 & B-cell-attracting chemokine-1 (BCA-1) \\
\hline CXCL14 & BRAK/bolekine \\
\hline CXCL16 & \\
\hline \multicolumn{2}{l}{ The CXXXC chemokine } \\
\hline CXC3CL1 & Fractalkine \\
\hline
\end{tabular}

\section{Chemokines and Their Receptors}

Within the CXC chemokine family, there are subdivisions on the basis of a structure/function domain reflecting the presence or absence of three amino acid residues (Glu-Leu-Arg; ELR motif) that are located before the first cysteine amino acid residue in the primary structure of these cytokines. CXC chemokines that are ELR positive are chemoattractants for neutrophils and have potent angiogenic activities. The ELR negative CXC chemokines are highly induced by interferons, are chemoattractants for mononuclear cells, and inhibit angiogenesis [60].

Seven CXC chemokine receptors have been identified, which are G protein-coupled receptors. CXCR1 and CXCR2 receptors are found on neutrophils, T lymphocytes, monocytes/macrophages, eosinophils, basophils, keratinocytes and mast cells and endothelial cells, and these bind to ELR+ chemokines [61]. CXCR3 is expressed on activated T lymphocytes and HUMVECs and is the receptor for CXCL9, CXCL10 and CXCL11. The CXCL12 receptor is CXCR4 and is the cofactor for lymphotropic HIV-1, and in contrast to CXCR3, CXCR4 appears to be expressed on unactivated T-lymphocytes [61]. There are other chemokine receptors that bind chemokines without a subsequent signal-coupling event. The DARC receptor binds both CXC and CC chemokines without apparent signal coupling. This receptor, first discovered on human erythrocytes, is thought to represent a reservoir for chemokines, binding pro-inflammatory chemokines when concentration levels are high during tissue inflammation and releasing them when chemokine levels are lower [62, 63]. A second nonsignalling chemokine receptor is the D6 receptor, which binds several CC chemokines with high affinity, including CCL2, CCL4, CCL5 and CCL7 ${ }^{-}$[64].

\section{The Role of CXC Chemokines in Pulmonary Fibrosis}

IPF is characterised by the progressive deposition of collagen within the interstitium and subsequent destruction of lung tissue $[10,12,65]$. While the mechanisms of cellular injury and the role of classic inflammatory cells remain unclear, CXCL8 is significantly elevated in IPF, as compared with either normal or sarcoidosis patients, and correlates with BALF presence of neutrophils. The alveolar macrophage is an important cellular source of CXCL8 in IPF [66]. In addition, BALF levels of CXCL8 in IPF 
may correlate with a worse prognosis [67]. More recently, CXCL13, which mediates B-cell trafficking in concert with its cognate receptor CXCR5 and is implicated in the pathogenesis of several immunologic disorders, was studied in the lung and plasma from IPF, COPD and control subjects. By way of biomarker utility, plasma CXCL13 was shown to be higher in IPF and highest in IPF complicated by pulmonary arterial hypertension or acute exacerbations. Interestingly, longitudinal measures of the chemokine over time (yearly) showing a relative rise of at least $50 \%$ from an earlier value were predictive of respiratory failure. The specificity of the biomarker to IPF was supported by less predictive abilities of the biomarker in COPD subjects [68].

\section{Vascular Remodelling in Pulmonary Fibrosis: The Role of CXC Chemokines}

The first to identify neovascularisation in IPF was Turner-Warwick in 1963, who demonstrated extensive neovascularisation within areas of pulmonary fibrosis, with anastomoses between the systemic and pulmonary microvasculature [69]. Further evidence of neovascularisation during the pathogenesis of pulmonary fibrosis has been uncovered in the bleomycin model of pulmonary fibrosis [70]. An imbalance in the levels of angiogenic chemokines (CXCL5, CXCL8), as compared with angiostatic chemokines (CXCL9, CXCL10, CXCL11), favouring net angiogenesis has been demonstrated in animal models but additionally in tissue specimens from patients with IPF [71]. Renzoni et al. have shown evidence of vascular remodelling in both IPF and fibrosing alveolitis associated with systemic sclerosis [72]. Cosgrove et al. demonstrated a relative absence of vessels in the fibroblastic foci of IPF, providing further support for the concept of vascular remodelling in IPF. They also noted significant vascularity in the areas of fibrosis around the fibroblastic foci, with numerous abnormal vessels in the regions of severe architectural distortion [73]. These findings are similar to those of Renzoni and support the concept of regional heterogeneity of vascularity in IPF. This heterogeneity is an intuitive feature, as usual interstitial pneumonia, which is the pathological description of IPF, is defined by its regional and temporal heterogeneity [65].

CXCL14 is another CXC chemokine family member, known to be involved in the trafficking of various inflammatory mononuclear cells including immature dendritic cells, and can antagonise CXCL12-CXCR4 interactions [74-76]. Its expression in lung epithelium is modestly upregulated in healthy smokers and even more so in COPD and lung adenocarcinoma [77]. CXCL14 is also a potent inhibitor of angiogenesis, and recently it has been demonstrated to be elevated in IPF lung tissue at the RNA and protein level and in blood, where it is postulated to have a role as a biomarker of Hedgehog signalling [75, 78]. With the availability of effective IPF therapeutic agents, there is now interest in clarifying the mechanisms of action of these agents, and as a relevant example, nintedanib is known to inhibit tumour angiogenesis in lungs by acting on endothelial cells, pericytes and smooth muscle cells, though the role for nintedanib-mediated angiogenesis regulation in IPF awaits further study $[79,80]$. 


\section{Macrophages}

Macrophages, highly plastic and diverse types of cell which arise from monocyte lineage as part of the mononuclear phagocytic system, are important for host defence including antimicrobial activities while also having a recognised role in wound healing and fibrogenesis through the production and release of chemokines capable of recruiting inflammatory cells and leading to the proliferation and activation of collagen-secreting myofibroblasts (Fig. 6.6). While much of the data linking macrophages to IPF pathogenesis has centred on the use of imperfect models of lung fibrosis such as the murine bleomycin model, such models provide important insights that can be extended by supportive human biospecimen data, and the plausibility of a macrophage role in IPF is suggested by various findings, not least of all
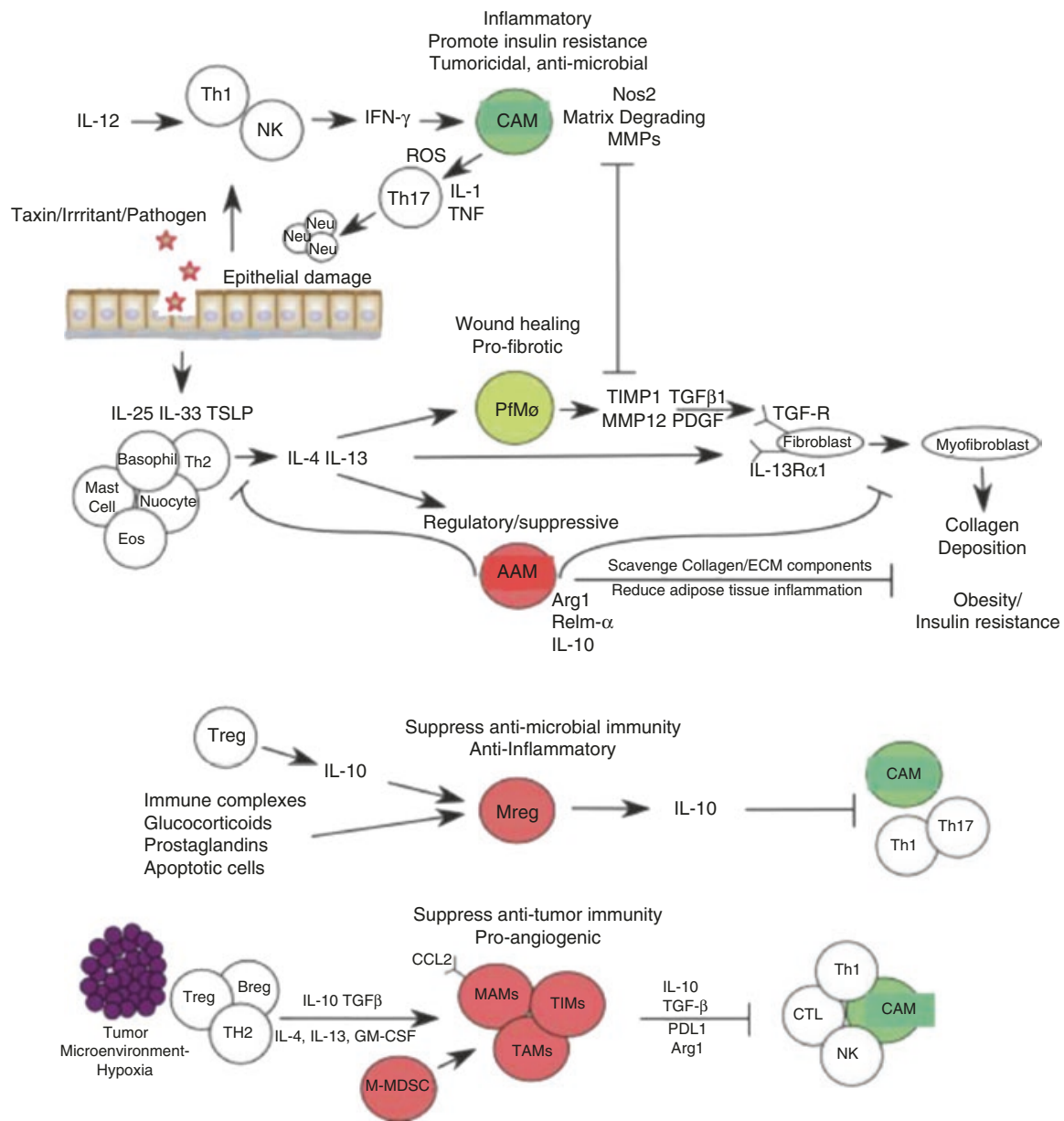
the expansion of alveolar macrophages in BAL fluid in response to chronic smoking, an IPF risk factor, and in IPF itself [81-83]. Before the vast diversity of cells and functionality within the mononuclear phagocytic system was better appreciated, working classifications were arrived at, such as term M1 or classically activated macrophages ("inflammatory phenotype"), to describe macrophages that activate immune defences (e.g. TNF- $\alpha$, IL-1, IL-6, ROS, NOS2) in response to pathogens or tissue injury that elicit Th1 inflammation. In contrast, M2 or alternatively activated macrophages are found in response to type II inflammation (e.g. IL-4, IL-13) and mediate wound healing and fibrosis among other reparative and homeostatic effects that can be subverted by recurring insults [84]. The complexity of macrophage involvement in airway epithelial homeostasis is apparent from the work of Cao and colleagues, who extended their previous discovery of a pulmonary vascular niche (involving a platelet-derived CXCL12 homolog called SDF1 which primes pulmonary capillary endothelial cells, or PCECs) that drives alveolar regeneration in mice, by studying this niche in models of lung fibrosis $[85,86]$. They identified a population of perivascular macrophages that interact with PCECs and perivascular fibroblasts following repetitive lung injury, to obstruct normal lung

Fig. 6.6 Macrophages exhibiting unique activation profiles regulate disease progression and resolution. Macrophages are highly plastic cells that adopt a variety of activation states in response to stimuli found in the local milieu. During pathogen invasion or following tissue injury, local tissue macrophages often adopt an activated or "inflammatory phenotype". These cells are commonly called "classically activated" macrophages (CAMs), because they were the first activated macrophage population to receive a formal definition. These macrophages are activated by IFN- $\gamma$ and/or following Toll-like receptor engagement, leading to the activation of the NF-k $\beta$ and Stat 1 signalling pathways, which in turn increases production of reactive oxygen and nitrogen species and pro-inflammatory cytokines like TNF- $\alpha$, IL- 1 and IL-6 that enhance anti-microbial and antitumour immunity, but may also contribute to the development of insulin resistance and dietinduced obesity. Epithelial-derived alarmins and the type-2 cytokines IL4 and IL13, in contrast, result in an "alternative" state of macrophage activation that has been associated with wound healing, fibrosis, insulin sensitivity and immunoregulatory functions. These wound-healing, pro-angiogenic and pro-fibrotic macrophages (PfM $\varnothing$ ) express TGF- $\beta 1$, PDGF, VEGF, WNT ligands and various matrix metalloproteinases that regulate myofibroblast activation and deposition of extracellular matrix components. Alternatively activated macrophages (AAMs) also express a variety of immunoregulatory proteins like arginase-1 (Arg1), Relm-alpha (Retn1a), Pd12 and I110 that regulate the magnitude and duration of immune responses. Therefore, in contrast to CAMs that activate immune defences, AAMs are typically involved in the suppression of immunity and re-establishment of homeostasis. Although type- 2 cytokines are important inducers of suppressive or immunoregulatory macrophages, it is now clear that several additional mechanisms can also contribute to the activation of macrophages with immunoregulatory activity. Indeed, IL10-producing Tregs, Fc gamma receptor engagement, engulfment of apoptotic cells and prostaglandins have also been shown to preferentially increase the numbers of regulatory macrophages (Mregs) that suppress inflammation and inhibit anti-microbial and anti-tumour defences. The tumour microenvironment itself also promotes the recruitment and activation of immune inhibitory cells, including those of the mononuclear phagocytic series such as myeloid-derived suppressor cells (MDSCs), tumourinfiltrating macrophages (TIMs), tumour-associated macrophages (TAMs) and metastasis-associated macrophages (MAMs) that promote angiogenesis and tumour growth, while suppressing anti-tumour immunity. (From Ref. [84]) 
regeneration and contribute to pulmonary fibrosis by suppressing PCEC-derived CXCR7 expression. Loss of CXCR7 on PCECs leads to recruitment of vascular endothelial growth factor 1 (VEGFR1)-expressing perivascular macrophages that stimulate Wnt/ $\beta$-catenin-dependent upregulation of Notch ligand Jagged 1, with pro-fibrotic sequelae [85].

Abnormal persistence of pulmonary macrophages has also been found to have pro-fibrotic potential. The homeostasis of such cells is regulated in part by mitophagy (a type of autophagy with selective engulfment of dysfunctional mitochondria by autophagosomes), a quality-control process that can be switched on by mitochondrial reactive oxygen species [87]. Larson-Casey and co-workers implicated AKT1, one of the family of three serine/threonine protein kinases called AKT that ordinarily regulates cell survival, proliferation and differentiation, in the mitochondrial ROS generation and macrophage dysfunction that can lead to impaired mitophagy with resultant apoptosis resistance and the development of pulmonary fibrosis versus controls, employing a bleomycin murine model with conditional deletion of Aktl in macrophages. The authors additionally showed the alveolar macrophages obtained from IPF patients had evidence of increased mitophagy and resistance to apoptosis, consistent with a mechanistic role for these processes in IPF [88]. Another member of the AKT family, AKT2, has been shown to be necessary for bleomycininduced pulmonary fibrosis and inflammation, and in the fibrosis-resistant Akt2-/mice, adoptive transfer of wild-type macrophages restored the fibrosis in a process that also involved macrophage-specific production of TGF- $\beta 1$ and IL-13, raising interest in AKT2 as a potential therapeutic target for IPF [82].

IPF is characterised by high expression of the protein chitinase 3-like 1(CHI3L1 or YKL-40; the mouse homolog is Brp39) in the lung and in the circulation $[89,90]$. CHI3L1 has been found to augment expression of the alternative macrophage activation marker CD206 in response to IL-13, and CD206+ macrophages are present at increased levels in IPF lungs [91]. CHI3L1 also tracks with CCL18 expression, another marker of alternatively activated macrophages [90]. Zhou et al. also showed that CHI3L1 exerts context-specific effects in IPF, with translational data showing a potential inhibitory effect (low CHI3L1 levels) on lung injury in the bleomycininduced mouse model injury phase, while also showing an apparent augmentation of fibrogenesis (with high CHI3L1 levels) during the fibrotic phase in these animals. A YKL-40 transgenic mouse model was used to show an increased collagen, macrophage and lymphocyte accumulation in the lungs of the YKL-40-upregulated mice in response to bleomycin administration, with M2 markers markedly increased in lung tissue. The CD206 ${ }^{+}$macrophages in the transgenic YKL-40 mice showed in vitro evidence of stimulating fibroblasts to proliferate (but not transform into myofibroblasts). When total lung macrophages were depleted in the transgenic mice by liposomal clodronate, there was a significant reduction in bleomycin-induced pulmonary fibrosis [90].

Subsets of circulating monocytes have been identified in efforts to simplify the complexities of the mononuclear phagocytic system, including an "inflammatory monocyte" which highly expresses Ly6C, among other cell surface markers, that is recruited from the circulation in response to injury or infection [84]. In a study that used multiple in vivo depletional strategies and adoptive transfer techniques, circu- 
lating Ly6 $\mathrm{C}^{\text {hi }}$ monocytes were shown in separate models of pulmonary fibrosis to facilitate progression of the fibrosis with evidence also provided from human IPF BAL samples of markedly increased expression of the M2/alternatively activated marker CD163 on IPF alveolar macrophages vs control subjects [92]. More recently, an atypical monocyte has been characterised that shares features of a granulocyte (bi-lobed segmented nuclear shape and many cytoplasmic granules) and has been termed segregated-nucleus-containing atypical monocytes (SatM), bearing the marker signature of Ceacam1+Msr1+Ly6C-F4/80-Mac1+, and appears to be critical for fibrosis. The cells are regulated by CCAAT/enhancer binding protein $\beta$ (C/ $\mathrm{EBP} \beta$ ), and $C e b p b-/-$ chimaeric mice, lacking in SatM cells, were found to be protected from bleomycin-induced fibrosis, but not bleomycin-induced inflammation, and adoptive transfer of SatM into Cebpb-/- mice restored fibrosis susceptibility [93]. The lack of participation of this cell type in general inflammatory responses sets it apart from other monocytes and emphasises the redundancy of the simplistic M1/M2 classification, as multiple distinct phenotypes with disorder-specific behaviour are now being identified, creating an imperative for better understanding of how monocyte/macrophage biology pertains to IPF pathogenesis [93, 94].

\section{Neutrophils}

The increased numbers of neutrophils in IPF lungs versus normals has been described for decades, including a tendency for the cells to persist over time [5, 95]. Since the widespread adoption of idiopathic interstitial pneumonia classification with a stricter definition of IPF, it has become apparent that neutrophilic infiltrates are rare in IPF compared to the extent of fibrotic changes, with minimal interstitial inflammation usually evident on histopathologic inspection, and usually more mononuclear cells than neutrophils $[5,10,20]$. The mild degree of inflammation observed histopathologically in the UIP lesion of IPF is composed of mainly small lymphocytes, with scattered plasma cells, and occasional neutrophils and eosinophils. The location of the inflammation tends to be mainly in areas of collagen deposition or honeycomb change and is rare to be seen in otherwise structurally normal alveolar septa, and in contrast with historical opinion of IPF pathogenesis, the presence of severe inflammation now leads pathologists to suspect an alternative diagnosis other than UIP [10]. The neutrophil remains an important target in fibrotic disorders, including IPF, with evidence that the cells are implicated in bleomycininduced pulmonary fibrosis, where resistance to the fibrotic process is observed among neutrophil elastase-knockout mice [96]. Though originally approved in Japan for ARDS therapy, the neutrophil elastase inhibitor sivelestat appeared to increase the long-termmortality rate in mechanically ventilated patients with acute lung injury and is not being developed for ILD [97].

A more successful therapy, pirfenidone, possesses antifibrotic and antioxidant properties but also has anti-inflammatory effects, with the precise mechanism of action in IPF still unclear [2]. It is possible that acute effects ascribed to the drug may be relevant to the observed lower rate of IPF acute exacerbations with pirfeni- 
done. When rats are challenged with LPS, their BAL neutrophilia induced by LPS is inhibited in a dose-dependent manner by pretreatment with pirfenidone [98]. Among the other pleiotropic capabilities of pirfenidone is the ability to inhibit TNF- $\alpha$ secreted and cell-associated levels, although only at supratherapeutic doses in animal models, and the pulmonary anti-inflammatory activity of the drug has been shown to occur independently of TNF- $\alpha$ inhibition $[98,99]$. There is also evidence of it having an inhibitory effect on other Th1 inflammatory mediators including IL-1, IL-6, IL-8 and IL-12 [100]. Much is still to be learned regarding the extent of redundancy of pirfenidone's many effects in mediating its benefit in IPF.

Balestro and colleagues took an interesting approach to exploring hypothetical factors involved in IPF progression by performing pathologic quantification of cells from the explanted lung in slow progressors (annual decline in $\%$ predicted FVC $<10 \%, n=48$ ) and rapid progressors (annual decline in $\%$ predicted FVC $\geq 10 \%$, $n=25$ ) who underwent lung transplantation for IPF. Morphometric analysis showed the rapid progressors had a higher quantity of $\mathrm{CD} 45^{+}$leukocytes/mm [2] than the slow progressors $(p=0.01)$, with both innate (neutrophils $p=0.02$ and macrophages $p=0.04)$ andadaptive $\left(\mathrm{CD}^{+} p=0.01, \mathrm{CD}^{+} p=0.005\right.$ and $\mathrm{B}$ cells $p=0.003$ ) inflammatory cells expanded in numbers in rapid versus slow progressors [101]. It can be argued that although such an approach has the limitation of looking at the final pathway (consequences, not causes) of the disease, the "end stage" cannot account for the observed differences among rapid and slow progressors. In contrast, an earlier, smaller study that defined slow progressors by $>24$ months of symptoms before first presentation, and rapid progressors by $<6$ months of symptoms before first presentation, had 8 open lung biopsy cases from "rapid" progressors and 27 from "slow" progressors, with a semi-quantitative approach used to define various histopathologic parameters, including extent of interstitial inflammation, with no discriminative ability found among rapid versus slow progressors using histopathology at the time of IPF diagnosis, or using BAL cell profile in rapid versus slow progressors [102].

An intriguing new role for the neutrophil in mediating age-related pulmonary fibrosis, and hence of potential relevance to IPF and/or acute exacerbations of IPF, is a process termed NETosis, whereby activated neutrophils release their chromatin as neutrophil extracellular traps (NETs) [103]. These traps/NETs are composed of filaments of decondensed chromatin which extrudes from the dying neutrophil and are covered in granular proteins including antimicrobial peptides that can entrap pathogens [104]. A potentially protective role for such NETs is offset by the potential for tissue damage and inflammation from inappropriate NET release however, as has been demonstrated in a mouse model of transfusion-related acute lung injury, with NETs appearing in the lung microvasculature [105]. There is in vitro evidence that in response to exposure to fibrogenic agents including cigarette smoke extract and bleomycin, NET-derived components promote the differentiation of human lung fibroblasts into a myofibroblast phenotype and ex vivo evidence of NETs in close proximity to alpha-smooth muscle actin-expressing fibroblasts obtained from NSIP lung biopsies [106]. NETosis appears to be dependent on the citrullination of specific arginine residues on histone tails catalysed by the enzyme peptidylarginine 
deiminase 4 (PADI4). Using a padi4-deficient (padi4-/-) mouse model, Martinod et al. found that the incidence of age-induced pulmonary fibrosis was reduced (although not completely prevented) in padi4-/- mice than in wild-type mice. PADI4 is known to be highly expressed in inflammatory cellsand weakly expressed in lung tissue, leading the authors to surmise that reduced neutrophil NETosis is likely responsible for the antifibrotic effect, supported by the observation that neutrophils were primed for NETosis (as defined by a high percentage of citrullinated histone H3-positive neutrophils) in aged wild-type mice but not in aged padi4-/mice [107]. It is timely now for work to target PADI4 as a lung protection strategy in acute exacerbations of IPF.

\section{Adaptive Immunity}

There is increasing awareness of roles for adaptive immunity in IPF, potentially in initiation and/or disease progression. As mentioned earlier, lymphoid aggregates are a recognised pathologic feature of IPF lesions and in most if not all other disease settings are usually pathognomic for the presence of chronic immune responses [18, $19,108]$. From an immunity standpoint, there is a predominance of T cells in BAL fluid and lung tissue from IPF patient, with $\mathrm{CD}^{+} \mathrm{T}$ lymphocytes and mature dendritic cells found in the vicinity of fibroblastic foci and regions of high collagen deposition [17-19, 68]. The aggregates also display CD20+ B lymphocytes, which form cohesive clusters in the centre of these aggregates (Fig. 6.7). In contrast with COPD or idiopathic pulmonary arterial hypertension, these tertiary lymphoid structures have non-proliferating and non-apoptotic features and therefore are likely to have already been activated when recruited to the lymphoid aggregate lesions [18].

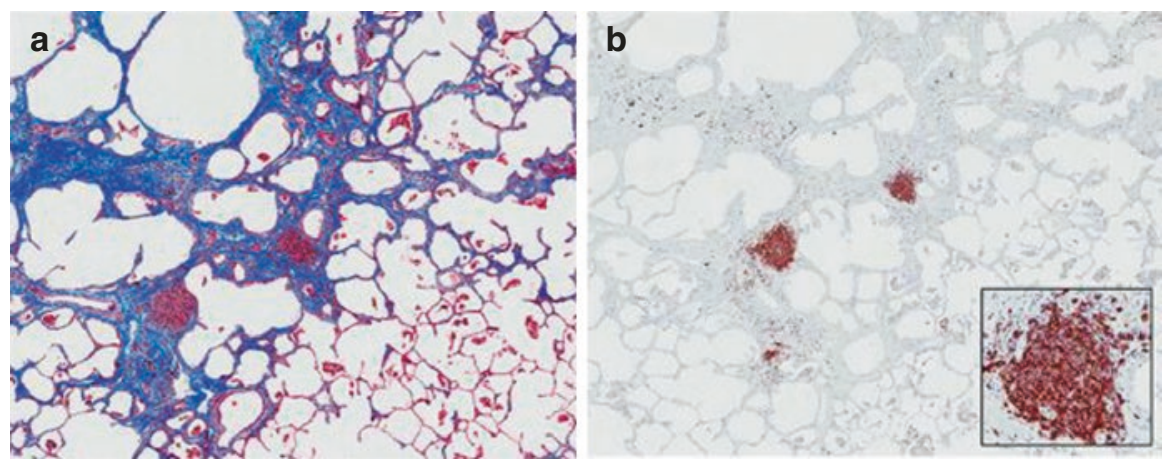

Fig. 6.7 Accumulation of CD20+ B-cell aggregates in the lung tissue of IPF patients around areas of pulmonary fibrosis that are normally absent in healthy lungs. (a) Masson's trichrome stain of the lung tissue of an IPF patient. (b) Immunohistochemical stain of CD20+ B cells in a serial section of the same tissue. The CD20+ aggregates accumulate in areas where there is fibrosis (blue areas in a). (From Ref. [110]) 
The tertiary lymphoid structures include mature dendritic cells, and because it is known that activated $\mathrm{T}$ cells within the lung retain competency in effector cytokine production, it is plausible that chronic pulmonary inflammation could result from reactivation of memory $\mathrm{T}$ cells by maturing dendritic cells within IPF lymphoid aggregates $[18,109,110]$.

In a study of 53 IPF patients' surgical lung biopsies, multivariate analyses showed that increasing fibroblastic foci scores were independently associated with greater declines in FVC and $\mathrm{DL}_{\mathrm{CO}}$ at 6 and 12 months of follow-up, but unexpectedly at the time of this study, increasing interstitial mononuclear cell infiltrates were also independently associated with lung function decline, though only at 6 months, leading the authors to postulate that such active inflammation could have a role early in the development of fibrosis, or represent an epiphenomenon related to fibroblastic activity [111].

In further support of immune mechanisms in IPF beyond the lung compartment, circulating $\mathrm{T}$ lymphocytes are abnormally activated in IPF versus normal and exhibit biased CD4 T-cell receptor $\beta$-chain variable (TCRBV) repertoires relating to oligoclonal proliferations that indicate the presence of cellular immune responses to antigens in IPF [112]. This does not occur in health, where $\mathrm{T}$ lymphocytes do not react to anatomically accessible self-antigens [113]. A prevalent feature of many chronic adaptive immune response states is that repeated cycles of antigen-induced proliferation will lead to the loss of cell surface CD28 expression in T lymphocytes [114]. Gilani and colleagues have demonstrated a similar form of marked differentiation of circulating $\mathrm{CD}^{+} \mathrm{T}$ cells in IPF with striking downregulation of CD28. Furthermore, these $\mathrm{CD}^{+}{ }^{+} \mathrm{CD} 28^{-}$cells had discordant expression of various activation and cytotoxic markers versus control cells and were also demonstrated in IPF lung tissues and associated with poor clinical outcomes [115].

Interleukin 13 and its receptors have received attention as a potential inflammatory target in IPF, given its secretion from Th2 lymphocytes, epithelial cells, innate lymphoid cells- 2 and macrophages and the recognition that IL-13 stimulates fibroblast proliferation and extracellular matrix synthesis by inducing TGF$\beta$, platelet-derived growth factor, connective tissue growth factor, collagen 1 and fibronectin production [95, 116]. Pulmonary tissue fibroblast cell lines from IPF patients exhibit the highest expression of IL-13 receptor alpha 1 and IL-13 receptor alpha 2 compared to similar cell lines from other idiopathic interstitial pneumonia patients and normals, and the proliferation of such IPF fibroblasts was inhibited by a chimeric protein of human IL-13 and a truncated version of Pseudomonas exotoxin [117].

There is controversy attached to a potential role for T-cell co-stimulatory cells in regulating lung fibrosis, with discordant regulatory effects identified in inducible T-cell co-stimulator (ICOS) depending on tissue compartment and species under study $[44,118]$. One study of IPF subjects utilised a discovery cohort $(n=45)$ and a separate replication cohort $(n=75)$ to validate a PBMC gene expression profile and found deceased expression of "the costimulatory signal during T-cell activation" Biocarta pathway in those who had a shorter transplant-free survival, with a putative four-gene biomarker of ICOS, CD28, ICK and ITK proving most predictive 
of such an adverse course, and the proteins likely to arise from CD4+CD28+ T cells. The biomarker showed an area under the (receiver operating characteristic) curve of $78.5 \%$ at 2.4 months for predicting death and lung transplant in the replication cohort, representing a two- to fourfold increased risk of patients dying of IPF or having a lung transplant [118]. Another study, which lacked a validation cohort, showed an ostensibly opposing direction of expression for ICOS (i.e. upregulation) in IPF versus normals. The authors speculated that in light of the known secretion of ICOS by activated T lymphocytes in IPF [119], there could be a correlation of a loss of ICOS expression on cells with elevated plasma ICOS levels and reduced transcription [44].

The IPF therapy nintedanib was first developed as an anti-angiogenic anti-cancer drug and functions as an ATP-competitive inhibitor of fibroblast growth factor receptor (FGFR)-1 and vascular endothelial growth factor receptor (VEGFR)-2. Its ability to inhibit platelet-derived growth factor receptor (PDGFR)- $\alpha$ and PDGFR- $\beta$ led to its therapeutic evaluation in IPF [80], and these mechanisms that diminish fibroblast-/myofibroblast-mediated fibrogenesis are likely to be responsible for the observed benefit of the drug in IPF. Nintedanib has also been shown in animal model systems to possess potent anti-inflammatory effects [120]. In a bleomycininduced mouse model of lung fibrosis, lymphocyte counts in BAL fluid were significantly lowered irrespective of the nintedanib dose delivered, in addition to reductions of the pro-inflammatory cytokine IL-1 $\beta$ in lung tissue, while in another in vivo model of silica-induced lung fibrosis, the injured mice that received nintedanib exhibited reductions in both neutrophils and lymphocytes, but not in macrophages in BAL, in addition to reduced lung tissue levels of IL- $1 \beta$ and another pro-inflammatory cytokine IL-6 [120].

\section{Autoimmunity and IPF}

The observations by independent investigators of lymphoid aggregates in perifibrotic lung tissue coupled with various autoantibodies in serum have led to a theory in IPF of a breakdown in immunological self-tolerance to antigens derived from injured and ageing airway epithelial cells [17-20, 110] (Fig. 6.8). The earliest descriptions of autoantibodies in what we now call IPF were hypothesised and described in the pre-pathological-standardisation era, when IPF/CFA included other IIP entities such as DIP and NSIP, with reactive IgG autoantibodies (molecular weight $70-90 \mathrm{kDa}$ ) identified in CFA patients against lung alveolar lining cells and DNA topoisomerase II $\alpha$ [121-123]. Nonetheless, idiopathic UIP is recognised to have a multiplicity of associations with autoantibodies, as outlined in Table 6.1 [124-136]. Both blood and BAL fluid of IPF patients have decreased CD4+ CD25+ FOXP3+ regulatory T cells or Tregs versus healthy controls and may be central to IPF pathogenesis, given their key role in the generation of immunologic tolerance which is a checkpoint to autoantibody production [137]. 


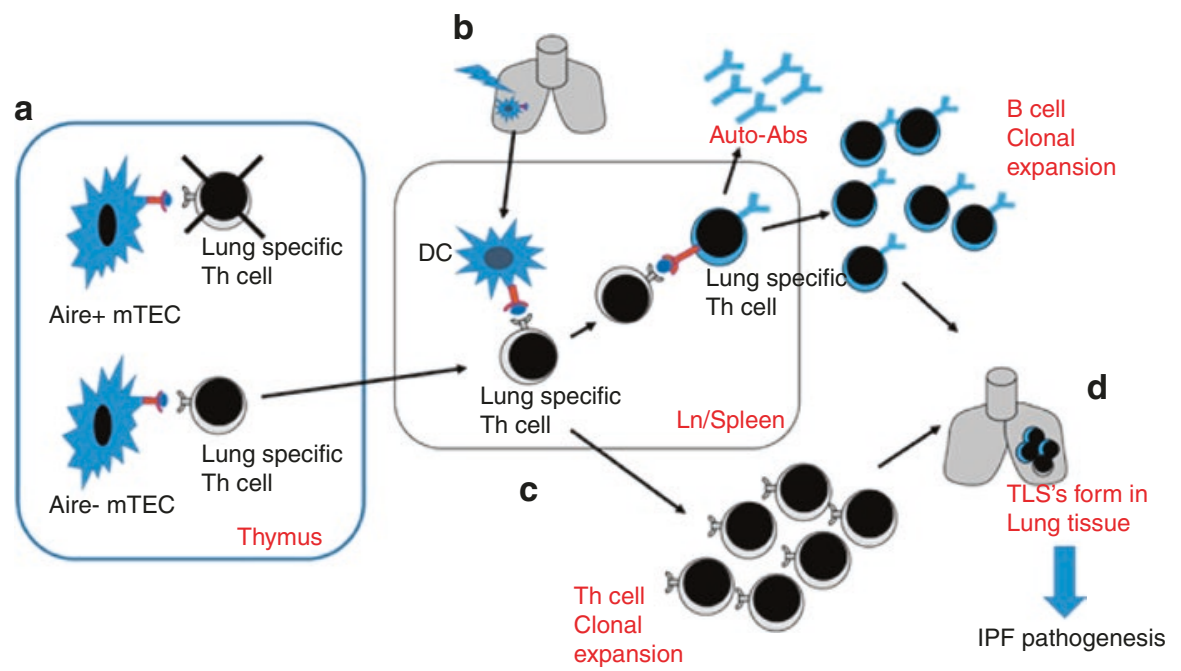

Fig. 6.8 Model of disease pathogenesis of IPF due to breakdown in self-tolerance to lung-specific protein antigens. (a) In the thymus, $\mathrm{AIRE}^{+}$mTECs can present self-antigens to developing thymocytes and self-reactive T cells are eliminated by apoptosis. In patients with APS-1 with mutations in which the Aire gene is faulty, mTECs fail to eliminate lung-specific T cells, and they complete maturation in the thymus and migrate to the periphery. (b) In response to injury in the lung, dendritic cells (DCs) can pick up and process lung-specific Ag and migrate to regional lymph nodes or spleen to present Ag to lung-specific Th cells. (c) The activated Th cells can provide help to Ag-specific B cells and both undergo clonal expansion, and Ag-specific B cells can mature as plasma cells and secrete autoantibodies into the blood. (d) Autoreactive T and B cells migrate to the lung to form TLSs, but they typically lack proliferating B cells and apoptotic cells in these sites, which are hallmarks of active germinal centres $[9,12,44]$. Due to chronic tissue damage, fibrosis develops and leads to IPF pathogenesis. (From Ref. [110])

Some of these associations of autoantibodies with IPF are plausibly pathogenic due to high expression of the target antigen in lung parenchymal tissues and/or have been linked to functional decline in IPF or other poor outcomes. For example, periplakin, a component of desmosomes but also strongly expressed in bronchial and alveolar epithelium, is one such target autoantigen, with circulating autoantibodies directed against it over-represented in the serum of IPF subjects compared to CTDILD, COPD or healthy subjects and associated with worse physiologic restriction and gas exchange on pulmonary function testing [126].

Type V collagen, a relatively less abundant collagen of pulmonary interstitial tissues compared to the major collagen in the lung, type I collagen, is ordinarily sequestered within fibrils of type I collagen but can become exposed to immune processes arising from lung remodelling of IPF, with subsequent development of anti-collagen $\mathrm{V}$ antibodies. This increase in type $\mathrm{V}$ collagen in IPF lung is associated with extent of fibrosis and predicts survival [138]. Interest is beginning to rise again in immunotherapies for IPF, exemplified by the knowledge that circulating autoantibodies against type $\mathrm{V}$ collagen are found in approximately $40 \%$ of patients with IPF [130], with even higher prevalence $(60 \%)$ in IPF of anti-collagen V reac- 
tive T cells using a trans-vivo delayed-type hypersensitivity test [139]. Nebulised type $\mathrm{V}$ collagen given in a murine bleomycin-induced fibrosis model prevented further collagen deposition and fibrosis by suppressing TGF- $\beta$ superfamily of genes [130]. A subsequent proof-of-concept phase I study using oral immunotherapy with bovine type $\mathrm{V}$ collagen given once daily for 6 months to IPF patients $(n=30)$ showed a suggestion of stabilisation of the IPF-progression marker MMP7, and a decrease in C1q binding, consistent with a potential immunological effect of therapy on anti-collagen $\mathrm{V}$ antibody binding and activity, when the lowest-dose cohort was compared to the highest-dose cohort [140].

Also illustrative of the case for autoimmune dysregulation in IPF progression is the identification of anti-heat shock protein (HSP)70 humoral and cellular autoreactivity found in 30/122 (25\%) IPF subjects versus 5/60 (3\%) control subjects and found to be associated with HLA allele biases, significantly worse FVC and a worse 1 -year survival of $40 \pm 10 \%$ versus $80 \pm 5 \%$ in controls (hazard ratio $=42$; $95 \%$ confidence interval $=2.0-8.6 ; p<0.0001$ ) [127]. These antibodies were seen in non-IPF ILD patients also but not linked to clinical progression in such patients. In contrast, the circulating autoantibodies widely obtained for clinical use in connective tissue disorders (including antinuclear antibody, extractible nuclear antigens such as Jo-1, etc.) have been shown to be no more frequently found in IPF subjects (22\% prevalence) versus healthy control subjects $(21 \%)$ and to be associated with a more favourable survival in IPF [141]. Others have found a positive serologic test rate in IPF subjects lacking clinical features of connective tissue disease, of $29 \%$ [142]. The IPF subjects in these latter studies are distinct from subjects that are now studied under the emerging label of interstitial pneumonia with autoimmune features (IPAF), where criteria from both serologic domains and clinical domains of connective tissue disorders would need to accompany the presence of ostensibly idiopathic UIP in order to be considered IPAF [143].

Recently, a study employing whole-proteomic analysis (>7900 proteins) of 45 ILD tissues (including IPF) in addition to fibrotic scleroderma skin samples and suitable controls for both organ types identified the most significant common factor among different idiopathic ILD and skin fibrosis samples to be a protein MZB1, localised to a terminally differentiated, antibody-producing tissue resident plasma B-cell phenotype, $\mathrm{MZB} 1^{+} / \mathrm{CD} 38^{+} / \mathrm{CD} 138^{+} / \mathrm{CD} 27^{+} / \mathrm{CD} 45 / \mathrm{CD} 20^{-}$, in both lung and skin fibrosis at high prevalence. These MZB1 plasma B cells were quite dispersed beyond tertiary lymphoid structures, though with a perivascular abundance, and levels correlated positively with tissue immunoglobulin G levels and DLCO, consistent with a common involvement of antibody-mediated autoimmunity in pulmonary and non-pulmonary fibrosis [136].

\section{Other Immunologically Active Cells}

Fibrocytes are bone marrow-derived mesenchymal cells of monocyte origin that have features of both macrophages and fibroblasts and found in circulating blood as 
well as sites of tissue fibrosis in a variety of injured organs including the lungs, where they have been postulated to be recruited through a CXCR4/CXCL12 axis [144-147]. It has been established that chronic inflammatory stimuli mediate differentiation, trafficking and accumulation of fibrocytes in autoimmune conditions characterised by the additional presence of fibrosis, such as asthma with chronic airflow obstruction due to subepithelial basement membrane fibrosis, or scleroderma, and several potential roles for the cell have been postulated in chronic inflammatory disease states based on observations to date (Fig. 6.9) [144]. Fibrocytes

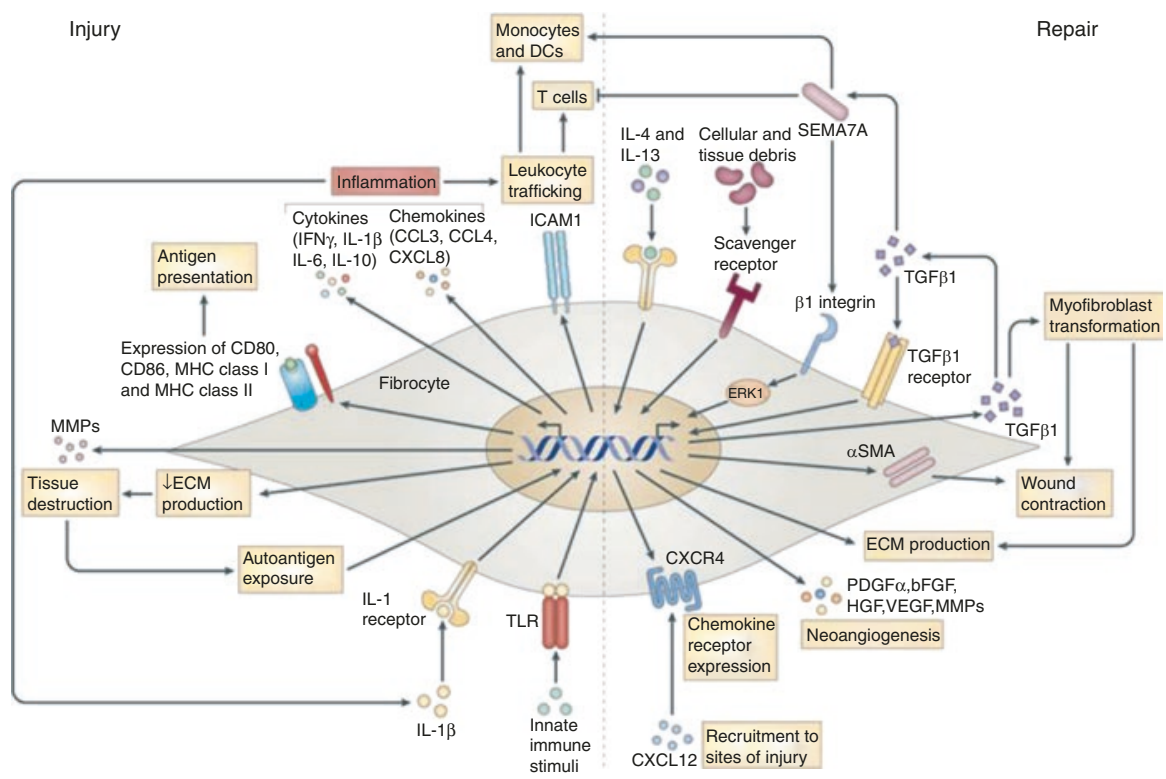

Nature Reviews | Immunology

Fig. 6.9 Using autoimmunity as a model, the possible roles of fibrocytes are proposed. In the setting of autoantigen exposure or acute injury, or following stimulation by interleukin-1 $\beta$ (IL-1 $\beta$ ), serum factors and innate immune stimuli, fibrocytes adopt a pro-inflammatory phenotype characterised by the secretion of interferon- $\gamma$ (IFN $\gamma$ ), IL-6, IL-8, CC-chemokine ligand 3 (CCL3) and CCL4. Leukocyte trafficking is enhanced through the expression of intercellular adhesion molecule 1 (ICAM1). Production of extracellular matrix (ECM) components is decreased, and antigenpresenting capabilities are increased by the expression of CD80, CD86 and MHC class I and II molecules. Tissue destruction may be increased by the expression of matrix metalloproteinases (MMPs). As the local milieu begins to favour repair and remodelling (or perhaps concurrently with ongoing injury in the right biological context), fibrocytes adopt a more reparative phenotype. In this setting, transforming growth factor- $\beta 1$ (TGF $\beta 1$ ) stimulates fibrocyte development through non-canonical pathways mediated by semaphorin 7A (SEMA7A) and $\beta 1$ integrin, although other TGF $\beta 1$-mediated signalling pathways may also be involved. SEMA7A could activate monocytes and dendritic cells (DCs) while dampening T-cell responses. ECM production is also stimulated by T helper 2 ( $\mathrm{T}_{\mathrm{H}} 2$ ) cell cytokines (such as IL-4 and IL-13), as well as by exposure to apoptotic cells and cellular debris. Myofibroblast transformation is promoted by TGF $\beta 1$. Platelet-derived growth factor- $\alpha$ (PDGF $\alpha)$, IL-10, vascular endothelial growth factor (VEGF), hepatocyte growth factor (HGF) and basic fibroblast growth factor (bFGF) support neoangiogenesis, and recruitment to sites of injury is promoted by the expression of chemokine receptors such as CXC-chemokine receptor 4 (CXCR4). $\alpha$ SMA $\alpha$-smooth muscle actin, CXCL CXC-chemokine ligand, ERK extracellular signal-regulated kinase, TLR Toll-like receptor. (From Ref. [144]) 
gained increased attention in IPF with the finding of significantly higher levels of circulating CD45+, collagen 1+ fibrocytes in stable IPF patients versus ARDS or healthy control subjects, and in this study the levels of circulating fibrocytes increased further during acute exacerbations of IPF, in addition to being associated with worse survival [148]. Further proof for this biomarker principle came in a study of patients with Hermansky-Pudlak syndrome, a group of autosomal recessive disorders that result in oculocutaneous albinism, and (in the case of genotypes HPS1, HPS-2 and HPS-4) development of interstitial pneumonia of a UIP-like pathology that can be slowed by pirfenidone $[149,150]$. In a cross-sectional analysis of 66 patients with Hermansky-Pudlak syndrome and 12 age-matched controls, circulating fibrocytes (CD45+, Col1+) and activated fibrocytes (also positive for $\alpha$-smooth muscle actin) were markedly elevated in certain subjects with HPS who had ILD but not in ILD-free HPS or controls. They also followed patients with longitudinal fibrocyte estimations and showed episodic spikes in levels of fibrocytes that strongly associated with death from pulmonary fibrosis [151]. Due to conflicting studies regarding whether or not these cells can differentiate in vivo into myofibroblasts, it is perhaps more likely that fibrocytes are contributing to fibrogenesis through paracrine signalling, potentially influencing other inflammatory cells or resident lung cells in the vicinity such as fibroblasts, endothelial or airway epithelial cells [147, $152,153]$. A proposed model of the potential role for fibrocytes in tissue injury, repair and remodelling is shown in Fig. 6.10 [144]. A key issue that has muddied the waters in the elucidation of fibrocyte pathobiology is the lack of consistency across investigative laboratories as to what cell marker sets should be used to define fibrocytes and other technical factors that may affect reproducibility of findings [153].

\section{Inflammation and Acute Exacerbations of IPF}

The natural history of IPF can be interspersed by an acute, clinically significant respiratory deterioration characterised by evidence of new, widespread alveolar abnormalities, termed an acute exacerbation [154]. There is uncertainty as to the aetiology of these deadly exacerbations, but the prevailing view is that acute factors known to cause acute lung injury, such as microbial infection, microaspiration or mechanical lung stretch, interact with chronic factors including the upregulated population of fibroblasts and dysfunctional epithelial cells, to bring about the widespread acute lung injury that typifies these exacerbations, with hyaline membrane formation and interstitial oedema, in addition to a variable presence of neutrophils $[154,155]$. In the acute exacerbation of IPF setting, there has long been a theory that viruses in particular play a key aetiologic role. In contrast, a study of 43 patients who were experiencing an acute exacerbation found that the majority of such IPF subjects appeared to have no evidence of viral infection when BALF and serum were subjected to multiplex PCR, pan-viral microarray and high-throughput cDNA sequencing for viruses. A significant minority, 28\%, had evidence of torque teno virus and significantly more so than in stable controls, with a similar rate of this virus also found in acute lung injury controls [156]. The ability of nintedanib and 


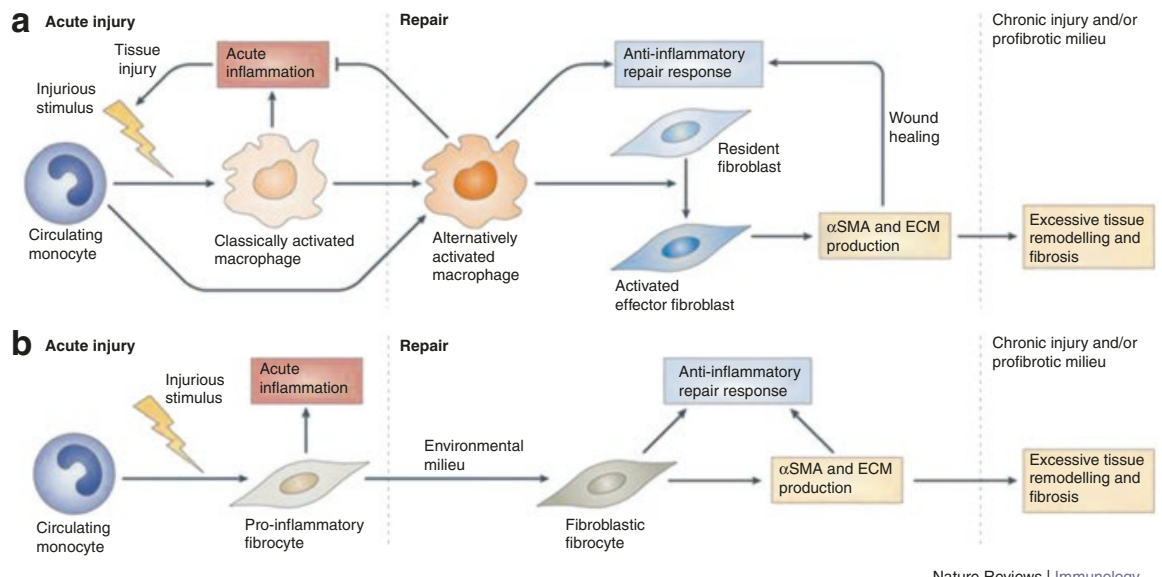

Fig. 6.10 (a) Current models suggest that in response to injurious stimuli, classically activated macrophages infiltrate diseased organs and mediate a programme of acute inflammation. As injury ceases and repair begins, the macrophage phenotype shifts towards that of alternative activation to dampen inflammation and promote repair. These macrophages stimulate resident fibroblasts to adopt an activated effector state characterised by the expression of $\alpha$-smooth muscle actin ( $\alpha \mathrm{SMA})$ and enhanced extracellular matrix (ECM) production. In the setting of severe or persistent injury, or a profibrotic milieu, this response shifts towards excessive remodelling and fibrosis. (b) This model of many cells acting together is contradicted by the finding that fibrocytes have properties of both macrophages and fibroblasts. Thus, an alternative model of repair is proposed in which fibrocytes traffic to injured organs, where they participate in the inflammatory events that are also attributed to macrophages. As damage subsides, fibrocytes respond to local cues to downregulate their inflammatory responses and adopt a fibroblastic phenotype to promote repair and, in some pathological conditions, remodelling and fibrosis. (From Ref. [144])

pirfenidone to favourably impact on the incidence of acute exacerbations of IPF may relate to some or all of purported mechanisms of action of these agents, including potentially their anti-inflammatory effects. Pirfenidone also appears to have a beneficial effect on respiratory-related hospitalisations in IPF patients, events that are more common than purely acute exacerbations of IPF, and, for example, included pneumonia events [157].

The prognosis for IPF acute exacerbations, which is poor, has been evaluated alongside putative serum biomarkers, one of which is anti-heat shock protein 70 autoantibody level. In a study of 122 IPF patients and 60 controls, anti-HSP70 IgG autoantibodies were found in $25 \%$ and $3 \%$, respectively, and in IPF the autoantibody was associated with IPF CD4 T-lymphocyte and monocyte autoreactivity, greater FVC reduction and a shorter 1-year survival [127]. A small trial of 11 critically ill IPF subjects with acute exacerbation, 7 of whom had autoantibodies against HEp-2 cells, investigated outcomes following treatment with rituximab and therapeutic plasma exchanges and in some cases the further addition of intravenous immunoglobulin. An intention-to-treat analysis (including the two withdrawals prior to treatment) showed a 1-year survival advantage versus 20 historical controls 
(controls from within 2 years prior to the experimental therapy enrolment) of 39\% versus $0 \%$ (and $46 \pm 15 \%$ versus $0 \%$ for 11 treated subjects vs controls), although the lack of a prospective control group and potential confounding limit interpretation of the results [158].

\section{Future and Ongoing Work}

The pleiotropic effects and substantial redundancy that constitute the various immunomodulatory pathways implicated to date in IPF make for great difficulties in reductionist approaches to deciphering cause or effect of a given pathway target molecule. It is impossible with our present knowledge to conclusively state whether or not the indisputably present immune dysfunction of IPF is a primary cause, a cause of progressive disease, or a secondary response such as immunosenescence, or a phenomenon downstream of more pathogenic initial injuries in ageing lungs. There is a distinct possibility that immune-mediated IPF endotypes have been overlooked in studies of unselected immunomodulatory therapies for IPF to date [159, 160]. Interest is now increasing again in therapies that attempt to address immune or inflammatory mechanisms in IPF. From a microbiomic perspective, there are at least two clinical trials planned or underway to evaluate the impact of co-trimoxazole or doxycycline on IPF-relevant clinical outcomes in selected patients with IPF (Clean-up IPF Trial, ClinicalTrials.gov identifier NCT02759120 and EME-TIPAC, EudraCT number 2014-004058-32) [159]. Based on a recent methodologically flawed but thought-provoking retrospective multicohort analysis of 11 IPF patients treated with the well-tolerated mycophenolate modafinil (MMF, a potent inhibitor of lymphocyte purine synthesis and lymphocyte proliferation) who seemed to have a weak signal towards reduced FVC decline and reduced mortality compared to 30 IPF patients receiving other historically ineffective/harmful therapies or no therapies, the authors suggested a future trial of combination therapy of a licenced IPF antifibrotic agent and MMF, in a justifiable bid to better address inflammatory endotypes missed by current antifibrotic agents [161]. Efforts to modulate neutrophil function offer new promise in fibrotic disorders, including IPF. Inhibitors of NETosis (e.g. a PADI4 inhibitor) could plausibly offer hope as a therapy in the setting of acute exacerbations of IPF, where neutrophilia is a known feature [94]. An ongoing trial is examining the role of rituximab as a B-lymphocyte depletion strategy for the reduction of autoantibodies implicated in IPF, in the hope that clinical benefits will also be apparent, including the effect on acute exacerbations (ClinicalTrials.gov trial identifier: NCT01969409). Recent developments in the re-engineering of chimeric antigen receptor $\mathrm{T}$ cells specific for autoantigen-producing $\mathrm{B}$ cells, as a means of targeting therapy for autoimmune disease, offer an intriguing new tool to deplete autoreactive B-cell clones, while conserving normal adaptive immune processes, and an appropriate design may have utility in an autoimmune-mediated IPF [162]. Through investigative approaches such as those outlined above, it may yet prove possible to 
Table 6.2 Putative autoantibodies of relevance to idiopathic pulmonary fibrosis

\begin{tabular}{|c|c|c|}
\hline $\begin{array}{l}\text { Name of } \\
\text { autoantigen }\end{array}$ & Comment & References \\
\hline Annexin 1 & $\begin{array}{l}\text { The most abundant annexin in mammalian lung, expressed in } \\
\text { alveolar epithelial type II cells and macrophages. Identified in } \\
\text { acute exacerbations of IPF }\end{array}$ & [129] \\
\hline BPIFB1 & $12 \%$ of IPF patients had autoantibodies against BPIFB1 & [125] \\
\hline Collagen V & Linked to fibrosis extent and survival & [130] \\
\hline Cytokeratin 8 & $\begin{array}{l}\text { Epithelial cell cytoskeleton filament. Antibody complexes found } \\
\text { in } 29 \% \text { of IPF patients }\end{array}$ & [131] \\
\hline Cytokeratin 18 & Detected in sera of IPF patients & [132] \\
\hline Cytokeratin 19 & Detected in sera of IPF & [133] \\
\hline HSP70 & Associated with poor prognosis in IPF & [127] \\
\hline Interleukin-1a & Associated with rapidly progressive IPF & [128] \\
\hline KCNRG & A bronchial epithelial antigen & [134] \\
\hline LPLUNC1 & $\begin{array}{l}\text { A vomeromodulin-like protein expressed in human bronchiolar } \\
\text { epithelium. Linked with pulmonary fibrosis of autoimmune } \\
\text { polyglandular syndrome type I }\end{array}$ & [124] \\
\hline MZB1 & $\begin{array}{l}\text { Prevalent across ILD types and skin fibrosis, localised to B } \\
\text { lymphocytes }\end{array}$ & [136] \\
\hline Periplakin & $\begin{array}{l}\text { Found in IPF serum and BALF. Associated with more severe } \\
\text { disease }\end{array}$ & [126] \\
\hline Vimentin & $\begin{array}{l}\text { Autoantibody levels linked to serious adverse outcomes in two } \\
\text { separate IPF cohorts }\end{array}$ & [135] \\
\hline
\end{tabular}

exploit immune and inflammatory pathways in IPF that have been partially deciphered but that have thus far eluded successful therapeutic intervention (Table 6.2).

\section{References}

1. Richeldi L, Collard HR, Jones MG. Idiopathic pulmonary fibrosis. Lancet. 2017;389(10082):1941-52.

2. Spagnolo P, Wells AU, Collard HR. Pharmacological treatment of idiopathic pulmonary fibrosis: an update. Drug Discov Today. 2015;20(5):514-24.

3. Agostini C, Semenzato G. Immunology of idiopathic pulmonary fibrosis. Curr Opin Pulm Med. 1996;2(5):364-9.

4. Martinez FJ, Collard HR, Pardo A, et al. Idiopathic pulmonary fibrosis. Nat Rev Dis Primers. 2017;3:17074.

5. Hunninghake GW, Gadek JE, Lawley TJ, Crystal RG. Mechanisms of neutrophil accumulation in the lungs of patients with idiopathic pulmonary fibrosis. J Clin Invest. 1981;68(1):259-69.

6. Reynolds HY, Fulmer JD, Kazmierowski JA, Roberts WC, Frank MM, Crystal RG. Analysis of cellular and protein content of broncho-alveolar lavage fluid from patients with idiopathic pulmonary fibrosis and chronic hypersensitivity pneumonitis. J Clin Invest. 1977;59(1):165-75.

7. Dall'Aglio PP, Pesci A, Bertorelli G, Brianti E, Scarpa S. Study of immune complexes in bronchoalveolar lavage fluids. Respiration. 1988;54(Suppl 1):36-41. 
8. Bitterman PB, Rennard SI, Keogh BA, Wewers MD, Adelberg S, Crystal RG. Familial idiopathic pulmonary fibrosis. Evidence of lung inflammation in unaffected family members. $\mathrm{N}$ Engl J Med. 1986;314(21):1343-7.

9. Kropski JA, Pritchett JM, Zoz DF, et al. Extensive phenotyping of individuals at risk for familial interstitial pneumonia reveals clues to the pathogenesis of interstitial lung disease. Am J Respir Crit Care Med. 2015;191(4):417-26.

10. Katzenstein AL, Myers JL. Idiopathic pulmonary fibrosis: clinical relevance of pathologic classification. Am J Respir Crit Care Med. 1998;157(4 Pt 1):1301-15.

11. American Thoracic Society. Idiopathic pulmonary fibrosis: diagnosis and treatment. International consensus statement. American Thoracic Society (ATS), and the European Respiratory Society (ERS). Am J Respir Crit Care Med. 2000;161(2 Pt 1):646-64.

12. Travis WD, Costabel U, Hansell DM, et al. An official American Thoracic Society/European Respiratory Society statement: update of the international multidisciplinary classification of the idiopathic interstitial pneumonias. Am J Respir Crit Care Med. 2013;188(6):733-48.

13. Idiopathic Pulmonary Fibrosis Clinical Research N, Raghu G, Anstrom KJ, King TE Jr, Lasky JA, Martinez FJ. Prednisone, azathioprine, and N-acetylcysteine for pulmonary fibrosis. N Engl J Med. 2012;366(21):1968-77.

14. King TE Jr, Bradford WZ, Castro-Bernardini S, et al. A phase 3 trial of pirfenidone in patients with idiopathic pulmonary fibrosis. N Engl J Med. 2014;370(22):2083-92.

15. Richeldi L, du Bois RM, Raghu G, et al. Efficacy and safety of nintedanib in idiopathic pulmonary fibrosis. N Engl J Med. 2014;370(22):2071-82.

16. Douglas WW, Ryu JH, Schroeder DR. Idiopathic pulmonary fibrosis: impact of oxygen and colchicine, prednisone, or no therapy on survival. Am J Respir Crit Care Med. 2000;161(4 Pt 1):1172-8.

17. DePianto DJ, Chandriani S, Abbas AR, et al. Heterogeneous gene expression signatures correspond to distinct lung pathologies and biomarkers of disease severity in idiopathic pulmonary fibrosis. Thorax. 2015;70(1):48-56.

18. Marchal-Somme J, Uzunhan Y, Marchand-Adam S, et al. Cutting edge: nonproliferating mature immune cells form a novel type of organized lymphoid structure in idiopathic pulmonary fibrosis. J Immunol. 2006;176(10):5735-9.

19. Todd NW, Scheraga RG, Galvin JR, et al. Lymphocyte aggregates persist and accumulate in the lungs of patients with idiopathic pulmonary fibrosis. J Inflamm Res. 2013;6:63-70.

20. Nuovo GJ, Hagood JS, Magro CM, et al. The distribution of immunomodulatory cells in the lungs of patients with idiopathic pulmonary fibrosis. Mod Pathol. 2012;25(3):416-33.

21. Flaherty KR, Travis WD, Colby TV, et al. Histopathologic variability in usual and nonspecific interstitial pneumonias. Am J Respir Crit Care Med. 2001;164(9):1722-7.

22. Monaghan H, Wells AU, Colby TV, du Bois RM, Hansell DM, Nicholson AG. Prognostic implications of histologic patterns in multiple surgical lung biopsies from patients with idiopathic interstitial pneumonias. Chest. 2004;125(2):522-6.

23. Miki H, Mio T, Nagai S, et al. Fibroblast contractility: usual interstitial pneumonia and nonspecific interstitial pneumonia. Am J Respir Crit Care Med. 2000;162(6):2259-64.

24. Strieter RM. Con: inflammatory mechanisms are not a minor component of the pathogenesis of idiopathic pulmonary fibrosis. Am J Respir Crit Care Med. 2002;165(9):1206-7. discussion 7-8

25. Gifford AH, Matsuoka M, Ghoda LY, Homer RJ, Enelow RI. Chronic inflammation and lung fibrosis: pleotropic syndromes but limited distinct phenotypes. Mucosal Immunol. 2012;5(5):480-4.

26. White ES, Xia M, Murray S, et al. Plasma surfactant protein-D, matrix metalloproteinase-7, and osteopontin index distinguishes idiopathic pulmonary fibrosis from other idiopathic interstitial pneumonias. Am J Respir Crit Care Med. 2016;194(10):1242-51.

27. Richeldi L, Collard HR, du Bois RM, et al. Mapping the future for pulmonary fibrosis: report from the 17 th international colloquium on lung and airway fibrosis. Eur Respir $\mathrm{J}$. 2013;42(1):230-8. 
28. O'Neill LA, Golenbock D, Bowie AG. The history of toll-like receptors - redefining innate immunity. Nat Rev Immunol. 2013;13(6):453-60.

29. Plataki M, Koutsopoulos AV, Darivianaki K, Delides G, Siafakas NM, Bouros D. Expression of apoptotic and antiapoptotic markers in epithelial cells in idiopathic pulmonary fibrosis. Chest. 2005;127(1):266-74.

30. Desai TJ, Brownfield DG, Krasnow MA. Alveolar progenitor and stem cells in lung development, renewal and cancer. Nature. 2014;507(7491):190-4.

31. Ellson CD, Dunmore R, Hogaboam CM, Sleeman MA, Murray LA. Danger-associated molecular patterns and danger signals in idiopathic pulmonary fibrosis. Am J Respir Cell Mol Biol. 2014;51(2):163-8.

32. Bjermer L, Lundgren R, Hallgren R. Hyaluronan and type III procollagen peptide concentrations in bronchoalveolar lavage fluid in idiopathic pulmonary fibrosis. Thorax. 1989;44(2):126-31.

33. Mercer PF, Chambers RC. Innate immune signaling and stem cell renewal in idiopathic pulmonary fibrosis. Nat Med. 2016;22(11):1210-2.

34. Liang J, Zhang Y, Xie T, et al. Hyaluronan and TLR4 promote surfactant-protein-C-positive alveolar progenitor cell renewal and prevent severe pulmonary fibrosis in mice. Nat Med. 2016;22(11):1285-93.

35. Thomas AQ, Lane K, Phillips J 3rd, et al. Heterozygosity for a surfactant protein C gene mutation associated with usual interstitial pneumonitis and cellular nonspecific interstitial pneumonitis in one kindred. Am J Respir Crit Care Med. 2002;165(9):1322-8.

36. Sisson TH, Mendez M, Choi K, et al. Targeted injury of type II alveolar epithelial cells induces pulmonary fibrosis. Am J Respir Crit Care Med. 2010;181(3):254-63.

37. Cao P, Aoki Y, Badri L, et al. Autocrine lysophosphatidic acid signaling activates beta-catenin and promotes lung allograft fibrosis. J Clin Invest. 2017;127(4):1517-30.

38. Hackett NR, Butler MW, Shaykhiev R, et al. RNA-Seq quantification of the human small airway epithelium transcriptome. BMC Genomics. 2012;13:82.

39. Seibold MA, Wise AL, Speer MC, et al. A common MUC5B promoter polymorphism and pulmonary fibrosis. N Engl J Med. 2011;364(16):1503-12.

40. Fingerlin TE, Murphy E, Zhang W, et al. Genome-wide association study identifies multiple susceptibility loci for pulmonary fibrosis. Nat Genet. 2013;45(6):613-20.

41. Lee MG, Lee YH. A meta-analysis examining the association between the MUC5B rs $35705950 \mathrm{~T} / \mathrm{G}$ polymorphism and susceptibility to idiopathic pulmonary fibrosis. Inflamm Res. 2015;64(6):463-70.

42. Araki T, Putman RK, Hatabu H, et al. Development and progression of interstitial lung abnormalities in the Framingham Heart Study. Am J Respir Crit Care Med. 2016;194(12):1514-22.

43. Peljto AL, Zhang Y, Fingerlin TE, et al. Association between the MUC5B promoter polymorphism and survival in patients with idiopathic pulmonary fibrosis. JAMA. 2013;309(21):2232-9.

44. O'Dwyer DN, Norman KC, Xia M, et al. The peripheral blood proteome signature of idiopathic pulmonary fibrosis is distinct from normal and is associated with novel immunological processes. Sci Rep. 2017;7:46560.

45. Noth I, Zhang Y, Ma SF, et al. Genetic variants associated with idiopathic pulmonary fibrosis susceptibility and mortality: a genome-wide association study. Lancet Respir Med. 2013;1(4):309-17.

46. Bulut Y, Faure E, Thomas L, Equils O, Arditi M. Cooperation of toll-like receptor 2 and 6 for cellular activation by soluble tuberculosis factor and Borrelia burgdorferi outer surface protein a lipoprotein: role of toll-interacting protein and IL-1 receptor signaling molecules in toll-like receptor 2 signaling. J Immunol. 2001;167(2):987-94.

47. Zhu L, Wang L, Luo X, et al. Tollip, an intracellular trafficking protein, is a novel modulator of the transforming growth factor-beta signaling pathway. J Biol Chem. 2012;287(47):39653-63.

48. Kimman TG, Banus S, Reijmerink N, et al. Association of interacting genes in the toll-like receptor signaling pathway and the antibody response to pertussis vaccination. PLoS One. 2008;3(11):e3665. 
49. Rabinovich EI, Kapetanaki MG, Steinfeld I, et al. Global methylation patterns in idiopathic pulmonary fibrosis. PLoS One. 2012;7(4):e33770.

50. O’Dwyer DN, Armstrong ME, Trujillo G, et al. The toll-like receptor 3 L412F polymorphism and disease progression in idiopathic pulmonary fibrosis. Am J Respir Crit Care Med. 2013;188(12):1442-50.

51. Han MK, Zhou Y, Murray S, et al. Lung microbiome and disease progression in idiopathic pulmonary fibrosis: an analysis of the COMET study. Lancet Respir Med. 2014;2(7):548-56.

52. Molyneaux PL, Willis-Owen SAG, Cox MJ, et al. Host-microbial interactions in idiopathic pulmonary fibrosis. Am J Respir Crit Care Med. 2017;195(12):1640-50.

53. Huang Y, Ma SF, Espindola MS, et al. Microbes associate with host innate immune response in idiopathic pulmonary fibrosis. Am J Respir Crit Care Med. 2017;196:208-19.

54. Molyneaux PL, Cox MJ, Willis-Owen SA, et al. The role of bacteria in the pathogenesis and progression of idiopathic pulmonary fibrosis. Am J Respir Crit Care Med. 2014;190(8):906-13.

55. Moore BB, Moore TA. Viruses in idiopathic pulmonary fibrosis. Etiology and exacerbation. Ann Am Thorac Soc. 2015;12(Suppl 2):S186-92.

56. Thelen M, Stein JV. How chemokines invite leukocytes to dance. Nat Immunol. 2008;9(9):953-9.

57. Butler MWMP, Keane MP. Chemokines, Adipokines, and growth factors in the lung. In: Grippi JAE MA, Fishman JA, Kotloff RM, Pack AI, Senior RM, editors. Fishman's pulmonary diseases and disorders. 5th ed. New York: McGraw-Hill Medical; 2015. p. 327-40.

58. Strieter RM. Interleukin-8: a very important chemokine of the human airway epithelium. Am J Phys Lung Cell Mol Phys. 2002;283(4):L688-9.

59. Koelink PJ, Overbeek SA, Braber S, et al. Targeting chemokine receptors in chronic inflammatory diseases: an extensive review. Pharmacol Ther. 2012;133(1):1-18.

60. Strieter RM, Polverini PJ, Kunkel SL, et al. The functional role of the ELR motif in CXC chemokine-mediated angiogenesis. J Biol Chem. 1995;270(45):27348-57.

61. Strieter RM, Burdick MD, Mestas J, Gomperts B, Keane MP, Belperio JA. Cancer CXC chemokine networks and tumour angiogenesis. Eur J Cancer. 2006;42(6):768-78.

62. Dawson TC, Lentsch AB, Wang Z, et al. Exaggerated response to endotoxin in mice lacking the Duffy antigen/receptor for chemokines (DARC). Blood. 2000;96(5):1681-4.

63. Lee JS, Wurfel MM, Matute-Bello G, et al. The Duffy antigen modifies systemic and local tissue chemokine responses following lipopolysaccharide stimulation. J Immunol. 2006;177(11):8086-94.

64. Rot A. In situ binding assay for studying chemokine interactions with endothelial cells. J Immunol Methods. 2003;273(1-2):63-71.

65. Raghu G, Collard HR, Egan JJ, et al. An official ATS/ERS/JRS/ALAT statement: idiopathic pulmonary fibrosis: evidence-based guidelines for diagnosis and management. Am J Respir Crit Care Med. 2011;183(6):788-824.

66. Mukaida N. Pathophysiological roles of interleukin-8/CXCL8 in pulmonary diseases. Am J Phys Lung Cell Mol Phys. 2003;284(4):L566-77.

67. Southcott AM, Jones KP, Li D, et al. Interleukin-8. Differential expression in lone fibrosing alveolitis and systemic sclerosis. Am J Respir Crit Care Med. 1995;151(5):1604-12.

68. Vuga LJ, Tedrow JR, Pandit KV, et al. C-X-C motif chemokine 13 (CXCL13) is a prognostic biomarker of idiopathic pulmonary fibrosis. Am J Respir Crit Care Med. 2014;189(8):966-74.

69. Turner-Warwick M. Precapillary systemic-pulmonary anastomoses. Thorax. 1963;18:225-37.

70. Keane MP, Belperio JA, Arenberg DA, et al. IFN-gamma-inducible protein-10 attenuates bleomycin-induced pulmonary fibrosis via inhibition of angiogenesis. J Immunol. 1999;163(10):5686-92.

71. Keane MP, Belperio JA, Burdick MD, Lynch JP, Fishbein MC, Strieter RM. ENA-78 is an important angiogenic factor in idiopathic pulmonary fibrosis. Am J Respir Crit Care Med. 2001;164(12):2239-42.

72. Renzoni EA. Neovascularization in idiopathic pulmonary fibrosis: too much or too little? Am J Respir Crit Care Med. 2004;169(11):1179-80. 
73. Cosgrove GP, Brown KK, Schiemann WP, et al. Pigment epithelium-derived factor in idiopathic pulmonary fibrosis: a role in aberrant angiogenesis. Am J Respir Crit Care Med. 2004;170(3):242-51.

74. Salogni L, Musso T, Bosisio D, et al. Activin A induces dendritic cell migration through the polarized release of CXC chemokine ligands 12 and 14. Blood. 2009;113(23):5848-56.

75. Shellenberger TD, Wang M, Gujrati M, et al. BRAK/CXCL14 is a potent inhibitor of angiogenesis and a chemotactic factor for immature dendritic cells. Cancer Res. 2004;64(22):8262-70.

76. Tanegashima K, Suzuki K, Nakayama Y, et al. CXCL14 is a natural inhibitor of the CXCL12CXCR4 signaling axis. FEBS Lett. 2013;587(12):1731-5.

77. Shaykhiev R, Sackrowitz R, Fukui T, et al. Smoking-induced CXCL14 expression in the human airway epithelium links chronic obstructive pulmonary disease to lung cancer. Am J Respir Cell Mol Biol. 2013;49(3):418-25.

78. Jia G, Chandriani S, Abbas AR, et al. CXCL14 is a candidate biomarker for hedgehog signalling in idiopathic pulmonary fibrosis. Thorax. 2017;72:780-7.

79. Hilberg F, Roth GJ, Krssak M, et al. BIBF 1120: triple angiokinase inhibitor with sustained receptor blockade and good antitumor efficacy. Cancer Res. 2008;68(12):4774-82.

80. Wollin L, Wex E, Pautsch A, et al. Mode of action of nintedanib in the treatment of idiopathic pulmonary fibrosis. Eur Respir J. 2015;45(5):1434-45.

81. Butler MW, Hackett NR, Salit J, et al. Glutathione S-transferase copy number variation alters lung gene expression. Eur Respir J. 2011;38(1):15-28.

82. Nie Y, Sun L, Wu Y, et al. AKT2 regulates pulmonary inflammation and fibrosis via modulating macrophage activation. J Immunol. 2017;198(11):4470-80.

83. Schupp JC, Binder H, Jager B, et al. Macrophage activation in acute exacerbation of idiopathic pulmonary fibrosis. PLoS One. 2015;10(1):e0116775.

84. Wynn TA, Chawla A, Pollard JW. Macrophage biology in development, homeostasis and disease. Nature. 2013;496(7446):445-55.

85. Cao Z, Lis R, Ginsberg M, et al. Targeting of the pulmonary capillary vascular niche promotes lung alveolar repair and ameliorates fibrosis. Nat Med. 2016;22(2):154-62.

86. Rafii S, Cao Z, Lis R, et al. Platelet-derived SDF-1 primes the pulmonary capillary vascular niche to drive lung alveolar regeneration. Nat Cell Biol. 2015;17(2):123-36.

87. Chen Y, Azad MB, Gibson SB. Superoxide is the major reactive oxygen species regulating autophagy. Cell Death Differ. 2009;16(7):1040-52.

88. Larson-Casey JL, Deshane JS, Ryan AJ, Thannickal VJ, Carter AB. Macrophage Akt1 kinasemediated mitophagy modulates apoptosis resistance and pulmonary fibrosis. Immunity. 2016;44(3):582-96.

89. Korthagen NM, van Moorsel CH, Barlo NP, et al. Serum and BALF YKL-40 levels are predictors of survival in idiopathic pulmonary fibrosis. Respir Med. 2011;105(1):106-13.

90. Zhou Y, Peng H, Sun H, et al. Chitinase 3-like 1 suppresses injury and promotes fibroproliferative responses in mammalian lung fibrosis. Sci Transl Med. 2014;6(240):240ra76.

91. Lee CG, Hartl D, Lee GR, et al. Role of breast regression protein 39 (BRP-39)/chitinase 3-like-1 in Th2 and IL-13-induced tissue responses and apoptosis. J Exp Med. 2009;206(5):1149-66.

92. Gibbons MA, MacKinnon AC, Ramachandran P, et al. Ly6Chi monocytes direct alternatively activated profibrotic macrophage regulation of lung fibrosis. Am J Respir Crit Care Med. 2011;184(5):569-81.

93. Satoh T, Nakagawa K, Sugihara F, et al. Identification of an atypical monocyte and committed progenitor involved in fibrosis. Nature. 2017;541(7635):96-101.

94. Dimmeler S, Zeiher AM. Netting insights into fibrosis. N Engl J Med. 2017;376(15):1475-7.

95. Wick G, Grundtman C, Mayerl C, et al. The immunology of fibrosis. Annu Rev Immunol. 2013;31:107-35.

96. Chua F, Dunsmore SE, Clingen PH, et al. Mice lacking neutrophil elastase are resistant to bleomycin-induced pulmonary fibrosis. Am J Pathol. 2007;170(1):65-74.

97. Zeiher BG, Artigas A, Vincent JL, et al. Neutrophil elastase inhibition in acute lung injury: results of the STRIVE study. Crit Care Med. 2004;32(8):1695-702. 
98. Spond J, Case N, Chapman RW, et al. Inhibition of experimental acute pulmonary inflammation by pirfenidone. Pulm Pharmacol Ther. 2003;16(4):207-14.

99. Nakazato H, Oku H, Yamane S, Tsuruta Y, Suzuki R. A novel anti-fibrotic agent pirfenidone suppresses tumor necrosis factor-alpha at the translational level. Eur J Pharmacol. 2002;446(1-3):177-85.

100. Ahidjo BA, Maiga MC, Ihms EA, et al. The antifibrotic drug pirfenidone promotes pulmonary cavitation and drug resistance in a mouse model of chronic tuberculosis. JCI Insight. 2016;1(14):e86017.

101. Balestro E, Calabrese F, Turato G, et al. Immune inflammation and disease progression in idiopathic pulmonary fibrosis. PLoS One. 2016;11(5):e0154516.

102. Selman M, Carrillo G, Estrada A, et al. Accelerated variant of idiopathic pulmonary fibrosis: clinical behavior and gene expression pattern. PLoS One. 2007;2(5):e482.

103. Viby NE, Isidor MS, Buggeskov KB, Poulsen SS, Hansen JB, Kissow H. Glucagon-like peptide-1 (GLP-1) reduces mortality and improves lung function in a model of experimental obstructive lung disease in female mice. Endocrinology. 2013;154(12):4503-11.

104. Brinkmann V, Reichard U, Goosmann C, et al. Neutrophil extracellular traps kill bacteria. Science. 2004;303(5663):1532-5.

105. Caudrillier A, Kessenbrock K, Gilliss BM, et al. Platelets induce neutrophil extracellular traps in transfusion-related acute lung injury. J Clin Invest. 2012;122(7):2661-71.

106. Chrysanthopoulou A, Mitroulis I, Apostolidou E, et al. Neutrophil extracellular traps promote differentiation and function of fibroblasts. J Pathol. 2014;233(3):294-307.

107. Martinod K, Witsch T, Erpenbeck L, et al. Peptidylarginine deiminase 4 promotes age-related organ fibrosis. J Exp Med. 2017;214(2):439-58.

108. Aloisi F, Pujol-Borrell R. Lymphoid neogenesis in chronic inflammatory diseases. Nat Rev Immunol. 2006;6(3):205-17.

109. Harris NL, Watt V, Ronchese F, Le Gros G. Differential T cell function and fate in lymph node and nonlymphoid tissues. J Exp Med. 2002;195(3):317-26.

110. Hoyne GF, Elliott H, Mutsaers SE, Prele CM. Idiopathic pulmonary fibrosis and a role for autoimmunity. Immunol Cell Biol. 2017;95:577-83.

111. Nicholson AG, Fulford LG, Colby TV, du Bois RM, Hansell DM, Wells AU. The relationship between individual histologic features and disease progression in idiopathic pulmonary fibrosis. Am J Respir Crit Care Med. 2002;166(2):173-7.

112. Feghali-Bostwick CA, Tsai CG, Valentine VG, et al. Cellular and humoral autoreactivity in idiopathic pulmonary fibrosis. J Immunol. 2007;179(4):2592-9.

113. Monaco C, Andreakos E, Kiriakidis S, Feldmann M, Paleolog E. T-cell-mediated signalling in immune, inflammatory and angiogenic processes: the cascade of events leading to inflammatory diseases. Curr Drug Targets Inflamm Allergy. 2004;3(1):35-42.

114. Fasth AE, Dastmalchi M, Rahbar A, et al. T cell infiltrates in the muscles of patients with dermatomyositis and polymyositis are dominated by CD28null T cells. J Immunol. 2009;183(7):4792-9.

115. Gilani SR, Vuga LJ, Lindell KO, et al. CD28 down-regulation on circulating CD4 T-cells is associated with poor prognoses of patients with idiopathic pulmonary fibrosis. PLoS One. 2010;5(1):e8959.

116. Passalacqua G, Mincarini M, Colombo D, et al. IL-13 and idiopathic pulmonary fibrosis: possible links and new therapeutic strategies. Pulm Pharmacol Ther. 2017;45:95-100.

117. Jakubzick C, Choi ES, Carpenter KJ, et al. Human pulmonary fibroblasts exhibit altered interleukin-4 and interleukin-13 receptor subunit expression in idiopathic interstitial pneumonia. Am J Pathol. 2004;164(6):1989-2001.

118. Herazo-Maya JD, Noth I, Duncan SR, et al. Peripheral blood mononuclear cell gene expression profiles predict poor outcome in idiopathic pulmonary fibrosis. Sci Transl Med. 2013;5(205):205ra136.

119. Ashley SL, Xia M, Murray S, et al. Six-SOMAmer index relating to immune, protease and Angiogenic functions predicts progression in IPF. PLoS One. 2016;11(8):e0159878. 
120. Wollin L, Maillet I, Quesniaux V, Holweg A, Ryffel B. Antifibrotic and anti-inflammatory activity of the tyrosine kinase inhibitor nintedanib in experimental models of lung fibrosis. J Pharmacol Exp Ther. 2014;349(2):209-20.

121. Wallace WA, Roberts SN, Caldwell H, et al. Circulating antibodies to lung protein(s) in patients with cryptogenic fibrosing alveolitis. Thorax. 1994;49(3):218-24.

122. Meliconi R, Bestagno M, Sturani C, et al. Autoantibodies to DNA topoisomerase II in cryptogenic fibrosing alveolitis and connective tissue disease. Clin Exp Immunol. 1989;76(2):184-9.

123. Turner-Warwick M, Doniach D. Auto-antibody studies in interstitial pulmonary fibrosis. Br Med J. 1965;1(5439):886-91.

124. Shum AK, DeVoss J, Tan CL, et al. Identification of an autoantigen demonstrates a link between interstitial lung disease and a defect in central tolerance. Sci Transl Med. 2009;1(9):9ra20.

125. Shum AK, Alimohammadi M, Tan CL, et al. BPIFB1 is a lung-specific autoantigen associated with interstitial lung disease. Sci Transl Med. 2013;5(206):206ra139.

126. Taille C, Grootenboer-Mignot S, Boursier C, et al. Identification of periplakin as a new target for autoreactivity in idiopathic pulmonary fibrosis. Am J Respir Crit Care Med. 2011;183(6):759-66.

127. Kahloon RA, Xue J, Bhargava A, et al. Patients with idiopathic pulmonary fibrosis with antibodies to heat shock protein 70 have poor prognoses. Am J Respir Crit Care Med. 2013;187(7):768-75.

128. Ogushi F, Tani K, Endo T, et al. Autoantibodies to IL-1 alpha in sera from rapidly progressive idiopathic pulmonary fibrosis. J Med Investig. 2001;48(3-4):181-9.

129. Kurosu K, Takiguchi Y, Okada O, et al. Identification of annexin 1 as a novel autoantigen in acute exacerbation of idiopathic pulmonary fibrosis. J Immunol. 2008;181(1):756-67.

130. Vittal R, Mickler EA, Fisher AJ, et al. Type V collagen induced tolerance suppresses collagen deposition, TGF-beta and associated transcripts in pulmonary fibrosis. PLoS One. 2013;8(10):e76451.

131. Dobashi N, Fujita J, Ohtsuki Y, et al. Circulating cytokeratin 8:anti-cytokeratin 8 antibody immune complexes in sera of patients with pulmonary fibrosis. Respiration. 2000;67(4):397-401.

132. Dobashi N, Fujita J, Murota M, et al. Elevation of anti-cytokeratin 18 antibody and circulating cytokeratin 18: anti-cytokeratin 18 antibody immune complexes in sera of patients with idiopathic pulmonary fibrosis. Lung. 2000;178(3):171-9.

133. Fujita J, Dobashi N, Ohtsuki Y, et al. Elevation of anti-cytokeratin 19 antibody in sera of the patients with idiopathic pulmonary fibrosis and pulmonary fibrosis associated with collagen vascular disorders. Lung. 1999;177(5):311-9.

134. Alimohammadi M, Dubois N, Skoldberg F, et al. Pulmonary autoimmunity as a feature of autoimmune polyendocrine syndrome type 1 and identification of KCNRG as a bronchial autoantigen. Proc Natl Acad Sci U S A. 2009;106(11):4396-401.

135. Yang Y, Fujita J, Bandoh S, et al. Detection of antivimentin antibody in sera of patients with idiopathic pulmonary fibrosis and non-specific interstitial pneumonia. Clin Exp Immunol. 2002;128(1):169-74.

136. Schiller HB, Mayr CH, Leuschner G, et al. Deep proteome profiling reveals common prevalence of MZB1-positive plasma B cells in human lung and skin fibrosis. Am J Respir Crit Care Med. 2017;196:1298-310.

137. Kotsianidis I, Nakou E, Bouchliou I, et al. Global impairment of CD4+CD25+FOXP3+ regulatory $\mathrm{T}$ cells in idiopathic pulmonary fibrosis. Am J Respir Crit Care Med. 2009;179(12):1121-30.

138. Parra ER, Teodoro WR, Velosa AP, de Oliveira CC, Yoshinari NH, Capelozzi VL. Interstitial and vascular type $\mathrm{V}$ collagen morphologic disorganization in usual interstitial pneumonia. J Histochem Cytochem. 2006;54(12):1315-25.

139. Bobadilla JL, Love RB, Jankowska-Gan E, et al. Th-17, monokines, collagen type $\mathrm{V}$, and primary graft dysfunction in lung transplantation. Am J Respir Crit Care Med. 2008;177(6):660-8. 
140. Wilkes DS, Chew T, Flaherty KR, et al. Oral immunotherapy with type V collagen in idiopathic pulmonary fibrosis. Eur Respir J. 2015;45(5):1393-402.

141. Lee JS, Kim EJ, Lynch KL, et al. Prevalence and clinical significance of circulating autoantibodies in idiopathic pulmonary fibrosis. Respir Med. 2013;107(2):249-55.

142. Moua T, Maldonado F, Decker PA, Daniels CE, Ryu JH. Frequency and implication of autoimmune serologies in idiopathic pulmonary fibrosis. Mayo Clin Proc. 2014;89(3):319-26.

143. Fischer A, Antoniou KM, Brown KK, et al. An official European Respiratory Society/ American Thoracic Society research statement: interstitial pneumonia with autoimmune features. Eur Respir J. 2015;46(4):976-87.

144. Reilkoff RA, Bucala R, Herzog EL. Fibrocytes: emerging effector cells in chronic inflammation. Nat Rev Immunol. 2011;11(6):427-35.

145. Bucala R, Spiegel LA, Chesney J, Hogan M, Cerami A. Circulating fibrocytes define a new leukocyte subpopulation that mediates tissue repair. Mol Med. 1994;1(1):71-81.

146. Song JS, Kang CM, Kang HH, et al. Inhibitory effect of CXC chemokine receptor 4 antagonist AMD3100 on bleomycin induced murine pulmonary fibrosis. Exp Mol Med. 2010;42(6):465-72.

147. Phillips RJ, Burdick MD, Hong K, et al. Circulating fibrocytes traffic to the lungs in response to CXCL12 and mediate fibrosis. J Clin Invest. 2004;114(3):438-46.

148. Moeller A, Gilpin SE, Ask K, et al. Circulating fibrocytes are an indicator of poor prognosis in idiopathic pulmonary fibrosis. Am J Respir Crit Care Med. 2009;179(7):588-94.

149. Suzuki T, Li W, Zhang Q, et al. Hermansky-Pudlak syndrome is caused by mutations in HPS4, the human homolog of the mouse light-ear gene. Nat Genet. 2002;30(3):321-4.

150. Gahl WA, Brantly M, Troendle J, et al. Effect of pirfenidone on the pulmonary fibrosis of Hermansky-Pudlak syndrome. Mol Genet Metab. 2002;76(3):234-42.

151. Trimble A, Gochuico BR, Markello TC, et al. Circulating fibrocytes as biomarker of prognosis in Hermansky-Pudlak syndrome. Am J Respir Crit Care Med. 2014;190(12):1395-401.

152. Kleaveland KR, Velikoff M, Yang J, et al. Fibrocytes are not an essential source of type I collagen during lung fibrosis. J Immunol. 2014;193(10):5229-39.

153. Moore BB, Kolb M. Fibrocytes and progression of fibrotic lung disease. Ready for showtime? Am J Respir Crit Care Med. 2014;190(12):1338-9.

154. Collard HR, Ryerson CJ, Corte TJ, et al. Acute exacerbation of idiopathic pulmonary fibrosis. An international working group report. Am J Respir Crit Care Med. 2016;194(3):265-75.

155. Song JW, Hong SB, Lim CM, Koh Y, Kim DS. Acute exacerbation of idiopathic pulmonary fibrosis: incidence, risk factors and outcome. Eur Respir J. 2011;37(2):356-63.

156. Wootton SC, Kim DS, Kondoh Y, et al. Viral infection in acute exacerbation of idiopathic pulmonary fibrosis. Am J Respir Crit Care Med. 2011;183(12):1698-702.

157. Ley B, Swigris J, Day BM, et al. Pirfenidone reduces respiratory-related hospitalizations in idiopathic pulmonary fibrosis. Am J Respir Crit Care Med. 2017;196:756-61.

158. Donahoe M, Valentine VG, Chien N, et al. Autoantibody-targeted treatments for acute exacerbations of idiopathic pulmonary fibrosis. PLoS One. 2015;10(6):e0127771.

159. Brownell R, Kaminski N, Woodruff PG, et al. Precision medicine: the new frontier in idiopathic pulmonary fibrosis. Am J Respir Crit Care Med. 2016;193(11):1213-8.

160. Maher TM. Precision medicine in idiopathic pulmonary fibrosis. QJM. 2016;109(9):585-7.

161. Nambiar AM, Anzueto AR, Peters JI. Effectiveness and safety of mycophenolate mofetil in idiopathic pulmonary fibrosis. PLoS One. 2017;12(4):e0176312.

162. Ellebrecht CT, Bhoj VG, Nace A, et al. Reengineering chimeric antigen receptor T cells for targeted therapy of autoimmune disease. Science. 2016;353(6295):179-84. 